FÁBIO TADEU MOURA LORENZETTI

\title{
Injeção roncoplástica: comparação entre etanol $50 \%$ e oleato de etanolamina $5 \%$ no tratamento do ronco
}

Tese apresentada à Faculdade de Medicina da Universidade de São Paulo para obtenção do título de Doutor em Ciências

Programa de Otorrinolaringologia

Orientador: Prof. Dr. Luiz Ubirajara Sennes

São Paulo

2011 


\title{
FÁBIO TADEU MOURA LORENZETTI
}

\section{Injeção roncoplástica: comparação entre etanol $50 \%$ e oleato de etanolamina $5 \%$ no tratamento do ronco}

\author{
Tese apresentada à Faculdade de Medicina \\ da Universidade de São Paulo para \\ obtenção do título de Doutor em Ciências * \\ Programa de Otorrinolaringologia \\ Orientador: Prof. Dr. Luiz Ubirajara Sennes
}

São Paulo

2011

* Esta versão possui algumas correções sugeridas pela Banca Examinadora. A versão original encontra-se disponível na Faculdade de Medicina da Universidade de São Paulo. 
Dados Internacionais de Catalogação na Publicação (CIP)

Preparada pela Biblioteca da

Faculdade de Medicina da Universidade de São Paulo

Creprodução autorizada pelo autor

Lorenzetti, Fábio Tadeu Moura

Injeção roncoplástica : comparação entre etanol 50\% e oleato de etanolamina

5\% no tratamento do ronco / Fábio Tadeu Moura Lorenzetti. -- São Paulo, 2011.

Tese(doutorado)--Faculdade de Medicina da Universidade de São Paulo.

Programa de Otorrinolaringologia.

Orientador: Luiz Ubirajara Sennes.

Descritores: 1.Apnéia do sono tipo obstrutiva 2.Escleroterapia 3.Ronco/terapia 4.Injeções 5.Etanol 6.Etanolamina

USP/FM/DBD-030/11 
Dedico este trabalho,

Aos meus queridos pais, Antonio Carlos e Terezinha, pelo amor, exemplo e apoio incondicional em todos os momentos de minha vida.

A minha irmã Taís e toda minha grande família que sempre estiveram ao meu lado. 


\section{AGRADECIMENTOS}

Agradeço

Ao Prof. Dr. Ricardo Ferreira Bento, Professor Titular da Disciplina de Otorrinolaringologia da Faculdade de Medicina da Universidade de São Paulo (FMUSP), pela incessante capacidade de melhorar a nossa Disciplina, pela luta constante em prol da otorrinolaringologia brasileira e pelo apoio em todas as fases do projeto.

Ao Prof. Dr. Luiz Ubirajara Sennes, coordenador do programa de pós-graduação da Disciplina de Otorrinolaringologia da FMUSP e orientador desta tese, pelo apoio ao longo deste trabalho, pelos conhecimentos transmitidos e por sua amizade.

Ao Dr. Michel Burihan Cahali, co-orientador desta tese, grande amigo e profissional admirável, pelos sábios ensinamentos ao longo de todos estes anos, pelo seu apoio em diversas situações, sua dedicação constante à ciência e por sua disponibilidade em sempre me ajudar.

Ao Dr. Gilberto Guanaes Simões Formigoni, professor e amigo, que foi a primeira pessoa a acreditar nesta minha idéia, que sempre me incentivou e me ensinou muito, inclusive participando do meu exame de qualificação.

Aos Prof. Dr. Richard L. Voegels, Prof. Dr. Ivan D. Miziara e Dr. Ronaldo Frizzarini, pelas importantes observações feitas no exame de qualificação, que me ajudaram na elaboração desta tese. Além de grandes 
amigos, vocês contribuíram muito para a minha formação.

Ao Dr. Raimar Weber pela grande ajuda na análise estatística e na revisão do texto, sem a qual seria muito difícil concluir o trabalho.

Aos Drs. Alexandre Nakasato e Bruno B. Duarte pela amizade, pelo apoio durante os procedimentos e pela leitura dos exames polissonográficos.

Aos Drs. Rui Imamura e Fábio Pinna, pelas reuniões de quarta-feira, nas quais pude aprofundar meu conhecimento na área estatística.

Ao Dr. Mauro Miguel Daniel, por sua dedicação na avaliação minuciosa dos exames de Ressonância Magnética.

A todos os professores da FMUSP que participaram da minha formação otorrinolaringológica, em especial ao Prof. Dr. Ossamu Butugan, do qual serei um eterno admirador.

Aos Drs. B. Tucker Woodson, Michael Friedman, Kasey Li, Peter Hwang e tantos outros que tive oportunidade de acompanhar e aprimorar meus conhecimentos nestes últimos anos.

Ao Dr. Scoth Brietzke que foi um dos principais responsáveis pelo meu interesse neste tema, com quem pude aprender e trocar experiências na Academia Americana de Otorrinolaringologia.

Aos Drs. José Antônio Pinto, Fernanda L.M. Haddad e Edilson Zancanella, amigos que me apoiaram em muitas ocasiões e me fizeram cada vez mais apaixonado pela medicina do sono.

À Dra. Ana Paula F.F. Dualibi, grande amiga e incentivadora, que me ajudou em vários momentos no decorrer deste trabalho. 
Aos Drs. Lucas T. Moura e Mauro T. Moura, meus únicos parentes médicos, amigos que me incentivaram e ajudaram no que foi preciso.

À Dra. Vanessa A.P.M. Lorenzetti por ter compartilhado comigo grande parte desta jornada.

A todos profissionais que trabalham comigo em Sorocaba, no BOS, no Spa Med e no consultório, agradeço pelo apoio e pela amizade.

À minha grande amiga Dra. Luciana Miwa Nita, a todos meus amigos de Residência Médica e de Faculdade, períodos dos quais sentirei eternas saudades.

A todos os residentes e outros profissionais que passaram pelo Grupo de Ronco do Hospital das Clínicas (HC) da FMUSP e que me ajudaram quando necessário.

A todos os funcionários do HCFMUSP que me ajudaram na execução do projeto.

A todos os pacientes que concordaram em participar da pesquisa e, muitas vezes com dificuldade, seguiram todas as etapas do protocolo.

À Fundação de Amparo à Pesquisa do Estado de São Paulo (FAPESP) pelo apoio financeiro ao projeto.

À Coordenação de Aperfeiçoamento de Pessoal de Nível Superior (CAPES) pela concessão da bolsa de doutorado.

A todas as pessoas que direta ou indiretamente me apoiaram nesta jornada, mas que eventualmente não foram citadas.

A Deus, por me dar sabedoria, saúde e perseverança para concluir este trabalho. 
"Toda verdade passa por três fases:

Primeiro, é ridicularizada;

Depois, é violentamente contrariada;

Por fim, é aceita como sendo evidente."

Arthur Schopenhauer 


\section{SUMÁRIO}

Lista de abreviaturas

Lista de símbolos

Lista de siglas

Lista de figuras

Lista de quadros, gráficos e tabelas

Resumo

Summary

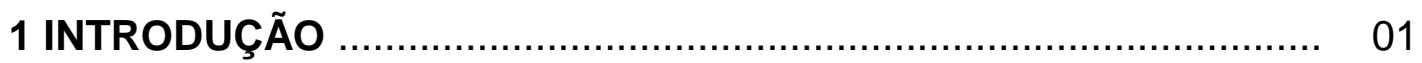

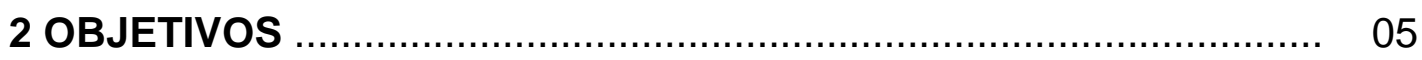

3 REVISÃO DA LITERATURA ....................................................... 07

4 CASUÍSTICA E MÉTODOS …..................................................... 13

4.1 Casuística .......................................................................... 14

4.1.1 Critérios de inclusão ........................................................... 14

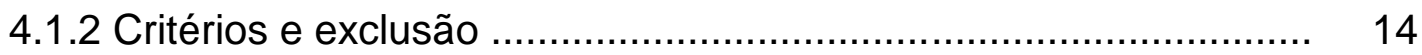

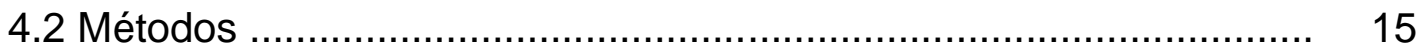

4.2.1 Avaliação clínica ................................................................... 19

4.2.2 Exame otorrinolaringológico …................................................ 21

4.2.2.1 Graduação do tamanho das tonsilas palatinas ......................... 21

4.2.2.2 Relação entre o palato mole e a língua .................................... 21

4.2.2.3 Estadiamento de Friedman ................................................. 22

4.2.3 Nasofibrolaringoscopia ....................................................... 23

4.2.4 Ressonância magnética .......................................................... 23

4.2.5 Polissonografia ................................................................ 26 
4.3 Análise estatística

5 RESULTADOS

6 DISCUSSÃO

7 CONCLUSÕES

REFERÊNCIAS

48

APÊNDICES

Apêndice 1 - Carta da Comissão de Ética

Apêndice 2 - Termo de Consentimento Livre e Esclarecido 


\section{LISTA DE ABREVIATURAS}

\begin{tabular}{ll} 
a.C. & Antes de Cristo \\
AP & Ântero-posterior \\
AHI & Apnea-hypopnea index \\
BMI & Body mass index \\
CC & Crânio-caudal \\
Dr. & Doutor \\
ed. & Edição \\
et al. & e outros \\
EVA & Escala visual analógica \\
IAH & Índice de apneia-hipopneia \\
IMC & Índice de massa corpórea \\
IR & Injeção roncoplástica \\
IS & injection snoreplasty \\
LAUP & Uvulopalatoplastia assistida por Laser \\
MRI & Magnetic resonance imaging \\
Nadir $\mathrm{SO}_{2}$ & Saturação mínima de $\mathrm{O}_{2}$ \\
O 2 & Oxigênio \\
p. & Página \\
Prof. & Professor \\
PSG & Polissonografia \\
rev. & Revista \\
\hline
\end{tabular}




$\begin{array}{ll}\text { RF } & \text { Radiofrequência } \\ \text { RM } & \text { Ressonância magnética } \\ \text { SED } & \text { Sonolência excessiva diurna } \\ \text { SAOS } & \text { Síndrome da Apneia Obstrutiva do Sono } \\ \text { V. } & \text { Volume } \\ \text { VAS } & \text { Visual analogue scale }\end{array}$




\section{LISTA DE SÍMBOLOS}

\begin{tabular}{|c|c|}
\hline $\mathrm{cm}$ & Centímetro \\
\hline $\mathrm{G}$ & Gauge \\
\hline $\mathrm{h}$ & Hora \\
\hline $\mathrm{kg}$ & Quilograma \\
\hline $\mathrm{kg} / \mathrm{m}^{2}$ & Quilograma por metro quadrado \\
\hline $\mathrm{m}$ & Metro \\
\hline $\mathrm{mm}$ & Milímetro \\
\hline $\mathrm{mg}$ & Miligrama \\
\hline $\mathrm{mL}$ & Mililitro \\
\hline ® & Marca registrada \\
\hline $\mathrm{s}$ & Segundo \\
\hline $\mathrm{T}$ & Tesla \\
\hline W & Watt \\
\hline / & Por \\
\hline$=$ & Igual \\
\hline$>$ & Maior \\
\hline$<$ & Menor \\
\hline$\%$ & Porcento \\
\hline
\end{tabular}




\section{LISTA DE SIGLAS}

$\begin{array}{ll}\text { AASM } & \text { Academia Americana de Medicina do Sono } \\ \text { ASA } & \text { Sociedade Americana de Anestesiologia } \\ \text { CAPPesq } & \text { Comissão de Ética para Análise de Projetos de Pesquisa } \\ \text { FMUSP } & \text { Faculdade de Medicina da Universidade de São Paulo } \\ \text { HCFMUSP } & \text { Hospital das Clínicas da Faculdade de Medicina da } \\ & \text { Universidade de São Paulo } \\ \text { USP } & \text { Universidade de São Paulo }\end{array}$




\section{LISTA DE FIGURAS}

Figura 1 Material utilizado para a injeção roncoplástica

Figura 2 Esquema simplificado das áreas de injeção: na primeira sessão (azul), na segunda sessão (verde) e na terceira sessão (amarela)

Figura 3 Injeção palatal da substância esclerosante, na linha média

Figura 4 Corte sagital mediano de RM. A linha amarela mostra o comprimento crânio-caudal do palato mole, enquanto a linha vermelha exibe a espessura ântero-posterior do palato mole

Figura 5 Corte sagital mediano de RM, onde todo o contorno do palato mole foi delimitado em verde, para cálculo da área palatal

Figura 6 Boxplot do escore de intensidade do ronco medido em escala visual analógica. Cada caixa apresenta a mediana (linha central) e o intervalo interquartil (p25p75); valores mínimo e máximo são apresentados pelos whiskers ("bigodes")

Figura 7 Variação antes e após tratamento dos escores da nota do ronco e da escala de Epworth para os grupos A e B . 
Figura 8 Ulceração palatal grande após sete (imagem esquerda), 14 (imagem central) e 21 dias da injeção (imagem

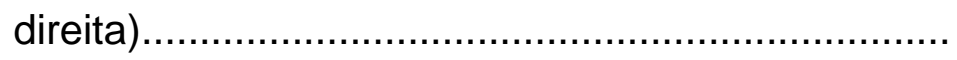




\section{LISTA DE QUADROS E TABELAS}

Quadro 1 Escala de sonolência de Epworth …….......................... 20

Quadro 2 Sistema de Estadiamento de Friedman ....................... 22

Tabela 1 Dados demográficos e referentes ao exame otorrinolaringológico .................................................. 30

Tabela 2 Escores medianos de intensidade de ronco medidos em escala visual analógica

Tabela 3 Variações pré e pós-aplicação da substância esclerosante na escala de Epworth e para os parâmetros polissonográficos avaliados

Tabela 4 Aspectos relacionados à aplicação da substância esclerosante

Tabela 5 Medidas do palato mole encontradas na ressonância magnética. 


\section{RESUMO}

Lorenzetti FTM. Injeção roncoplástica: comparação entre etanol $50 \%$ e oleato de etanolamina 5\% no tratamento do ronco [tese]. São Paulo: Faculdade de Medicina, Universidade de São Paulo; 2011. 79p.

INTRODUÇÃO: O ronco acomete grande parte da população e o seu tratamento é um desafio, pois existem muitas opções terapêuticas e esta escolha deve ser individualizada. Entre vários procedimentos palatais para tratamento do ronco e da apneia do sono, a injeção roncoplástica (IR) surgiu como uma alternativa econômica para alguns casos selecionados. OBJETIVOS: Avaliar os resultados da IR no tratamento do ronco, comparando o oleato de etanolamina $5 \%$ e o etanol $50 \%$. Além disso, descrever uma metodologia de aplicação própria e analisar seus resultados clínicos, complicações, medidas palatais por ressonância magnética (RM) e parâmetros polissonográficos. MÉTODOS: estudo clínico, duplo cego e randomizado, realizado de 2007 a 2010. Foram incluídos adultos roncadores com índice de apneia-hipopneia $(\mathrm{IAH})<15$. Critérios de exclusão: cirurgia palatal pregressa, IMC $>35$, obstrução nasal ou faríngea $>50 \%$ da via aérea, deformidade crânio-facial, gestação, ausência de acompanhante de quarto, alergia ou comorbidade grave. Sessões ambulatoriais de IR foram realizadas no palato mole (três pontos), máximo de três sessões, com quatro semanas de intervalo mínimo. Os pacientes foram divididos em dois grupos: um recebeu oleato de etanolamina $5 \%$ (A) e o outro, etanol $50 \%(B)$. A intensidade do ronco foi aferida por escala visual-analógica de 10cm (EVA). 
Foram analisados outros parâmetros clínicos, como sonolência e dor, além de RM e polissonografias. RESULTADOS: Dos 22 pacientes incluídos neste estudo ( $A=9$ / $B=13), 19(86,4 \%)$ apresentaram diminuição importante ou desaparecimento do ronco. A intensidade de ronco (EVA) decresceu nos dois grupos: de 8,0 para 3,0 no Grupo $A(p=0,007)$ e de 8,0 para 3,0 no Grupo B $(p=0,001)$. A escala de sonolência de Epworth diminui de 8,0 para 6,0 no Grupo A $(p=0,05)$ e de 11,0 para 5,0 no Grupo B $(p=0,005)$. A dor durante o procedimento, aferida em EVA, foi de 4,0 nos dois Grupos. Nos dias subseqüentes, a dor foi de 3,5 no Grupo A e 2,0 no Grupo B, sem diferença entre os grupos. Na amostra geral, o tempo médio para retorno a alimentação foi de 2,0 dias e a melhora do ronco ocorreu em 14,0 dias. Não foram observadas complicações graves. Vinte e um pacientes apresentaram afta palatal, mas nenhum desenvolveu fístula. Das medidas realizadas por $\mathrm{RM}$, a espessura palatal reduziu de 0,9 para $0,8 \mathrm{~cm}(p=0,34)$, o comprimento palatal diminuiu de 3,7 para $3,4 \mathrm{~cm}(\mathrm{p}=0,02)$ e a área palatal foi de 2,8 para $2,5 \mathrm{~cm}^{2}(p=0,29)$. Nas polissonografias, o IAH variou de 6,9 para 5,0 no Grupo A $(p=0,89)$ e de 5,2 para 6,3 no Grupo B $(p=0,22)$, enquanto a saturação mínima de $\mathrm{O}_{2}$ e os microdespertares não apresentaram alterações estatisticamente significantes. CONCLUSÕES: A IR mostrou resultados favoráveis no tratamento do ronco, porém não houve diferença entre os grupos que receberam oleato de etanolamina $5 \%$ e etanol $50 \%$. Nossa metodologia de aplicação reproduziu as taxas de sucesso de outros estudos, sem apresentar casos de fístula palatal ou complicações graves. As aferições por RM evidenciaram redução do comprimento palatal após as 
injeções. Não foram observadas alterações das variáveis polissonográficas após o procedimento.

Descritores: apneia do sono tipo obstrutiva, escleroterapia, ronco/terapia, injeções, etanol, etanolamina 


\section{SUMMARY}

Lorenzetti FTM. Injection Snoreplasty: comparison between ethanol and ethanolamine oleate in snoring treatment [thesis]. São Paulo: "Faculdade de Medicina, Universidade de São Paulo"; 2011. 79p.

BACKGROUND: Snoring affects a significant portion of the population and the treatment is a challenge, because there are many options and the choice should be individualized. Among various palatal procedures for the treatment of snoring and sleep apnea, the injection snoreplasty (IS) has emerged as an economic alternative for selected cases. OBJECTIVES: To evaluate IS in the snoring treatment, comparing $5 \%$ ethanolamine oleate and $50 \%$ ethanol. Also, to describe a distinct method of injection and analyze its clinical results, complications, palatal measures by resonance imaging (MRI), and polysomnographic parameters. METHODS: Clinical, double-blind, randomized trial conducted from 2007 to 2010. Adult snorers with apneahypopnea index $(\mathrm{AHI})<15$ were included. Exclusion criteria: previous palatal surgery, BMl> 35 , pharyngeal or nasal obstruction $>50 \%$ of the airway, craniofacial deformity, pregnancy, lack of room partner, allergy or severe comorbidity. IS outpatient sessions were held in the soft palate (three points), maximum of three sessions, with at least four weeks apart. Patients were randomized into two groups: $5 \%$ ethanolamine oleate $(A)$ or $50 \%$ ethanol $(B)$. The intensity of snoring was measured by visual-analogue scale of $10 \mathrm{~cm}$ (VAS). Other clinical parameters were analyzed, such as sleepiness and pain, as well as MRI and polysomnography. RESULTS: Of 22 patients 
enrolled in this study $(A=9 / B=13), 19(86.4 \%)$ showed significant reduction or disappearance of snoring. The snoring loudness (VAS) decreased in both groups: 8.0 to 3.0 in Group A ( $p=0.007)$ and 8.0 to 3.0 in Group B ( $p=0.001$ ). The Epworth Sleepiness Scale decreased from 8.0 to 6.0 in Group A ( $p=0.05)$ and from 11.0 to 5.0 in Group B $(p=0.005)$. The pain during the procedure, measured by VAS, was 4.0 in both Groups. On subsequent days, the pain was 3.5 in Group A and 2.0 in Group B, with no difference between groups. In the overall sample, the mean time to return to regular nourishing was 2.0 days and the improvement of snoring occurred in 14.0 days. There were no serious complications. Twenty-one patients had palatal ulcer, but none developed fistula. On the MRI measurements, the palatal thickness reduced from 0.9 to $0.8 \mathrm{~cm}(p=0.34)$, the palatal length decreased from 3.7 to $3.4 \mathrm{~cm}(\mathrm{p}=0.02)$ and the palatal area decreased from 2.8 to $2.5 \mathrm{~cm}^{2}(p=0.29)$. On polysomnography, the $\mathrm{AHI}$ ranged from 6.9 to 5.0 in Group A ( $p=0.89)$ and from 5.2 to 6.3 in Group B ( $p=0.22)$, while the lowest $\mathrm{O}_{2}$ saturation and arousals showed no statistically significant changes. CONCLUSIONS: IS showed favorable results in the treatment of snoring, but with no difference between the groups receiving $5 \%$ ethanolamine oleate and $50 \%$ ethanol. Our own methodology reproduced the success rates of other studies, without cases of palatal fistula or severe complications. Measures by MRI showed a reduction of the palatal length after the injections. There were no changes in polysomnographic variables after the procedure.

Descriptors: obstructive sleep apnea, sclerotherapy, snoring/therapy, injections, ethanol, ethanolamine 
1 INTRODUÇÃO 


\section{INTRODUÇÃO}

O ronco é um problema que acomete grande parte da população e que pode prejudicar a qualidade de vida não apenas do indivíduo roncador, mas também de quem dorme ao seu lado. Pode causar constrangimento quando o sujeito ronca perante outras pessoas e também gerar problemas conjugais. Muitas vezes, o ronco está acompanhado de apneias durante o sono, piorando a qualidade do sono e causando prejuízo no estado de saúde destes indivíduos.

A gênese do ronco pode estar envolvida com o relaxamento da musculatura faríngea durante o sono. Durante a passagem do ar, há uma vibração dos tecidos moles faríngeos que origina um ruído, conhecido como ronco. Na maioria dos casos, o principal local desta vibração é o palato mole (Brietzke, Mair, 2006).

De acordo com vários autores, a prevalência do ronco varia de 25 a $60 \%$ na população adulta, enquanto a síndrome da apneia obstrutiva do sono (SAOS) acomete de 2 a $24 \%$ dos adultos, de acordo com os critérios utilizados para diagnóstico. O estudo de Wisconsin analisou indivíduos entre 30 e 60 anos de idade e encontrou uma prevalência de SAOS em $4 \%$ dos homens e $2 \%$ das mulheres, considerando doentes os pacientes com índice de apneia-hipopneia $(\mathrm{IAH})>5$ por hora associado com sonolência excessiva diurna (SED). No entanto, quando o critério diagnóstico foi modificado para presença de $\mathrm{IAH}>15$ por hora, a prevalência da SAOS aumentou para $4 \%$ no 
sexo feminino e $9 \%$ no sexo masculino. Finalmente, quando o critério considerado foi apenas a presença de $\mid \mathrm{AH}>5$ por hora, a prevalência de apneia obstrutiva do sono se elevou para $9 \%$ das mulheres e $24 \%$ dos homens. Entretanto, em estudo recente na população de São Paulo, 1042 voluntários realizaram polissonografia e foi observada uma prevalência de SAOS em 32,8\% dos participantes (Lugaresi et al., 1980; Young et al., 1993; American Academy of Sleep Medicine, 1999; Tufik et al., 2010).

O tratamento de indivíduos portadores de ronco e SAOS é um desafio, pois existem várias opções terapêuticas e os resultados são muito variáveis. O sucesso de cada tratamento depende muito da escolha adequada e individualizada para cada paciente. Um dos principais fatores limitantes nesta escolha é o custo elevado de alguns tratamentos disponíveis, inviabilizando-os para grande parte da população.

A vibração do palato mole parece ser um dos principais fatores envolvidos na gênese do ronco. Desta forma, surgiram alguns tratamentos com objetivo de diminuir esta vibração mediante um enrijecimento do palato mole. Dentre estes, podemos citar a radiofrequência, os implantes palatais e a escleroterapia palatal (Savage, Steward, 2007; Brietzke, Mair, 2009).

O termo escleroterapia deriva do radical grego skleros que significa duro. Portanto, esclerosar significa provocar um endurecimento (fibrose) por processo inflamatório tecidual. Isto pode ser realizado de diversas maneiras, por vários tipos de agentes: térmicos, elétricos, irradiantes e químicos (Chao, Ayub, 2004). 
A escleroterapia química é utilizada na medicina há séculos, com inúmeras aplicabilidades terapêuticas descritas: varizes, telangiectasias, nódulos e cistos diversos, higromas císticos, hidroceles, hemorragia digestiva alta por varizes esofágicas, tumores renais, fissuras anais, hérnias inguinais, dentre outras (Strauss, 1943; Levinson, 2001; Chao, Ayub, 2004).

A escleroterapia química do palato mole para o tratamento do ronco em humanos já foi estudada por alguns autores. As drogas utilizadas e as metodologias de aplicação empregadas são variáveis na literatura. Dentre as substâncias esclerosantes já utilizadas para esta finalidade estão o psiliato de sódio, o tetradecil sulfato de sódio, o etanol e o polidocanol (Strauss, 1943; Brietzke, Mair, 2001; Brietzke, Mair, 2004; Iseri, Balcioglu, 2005; Brietzke, Mair, 2009).

O presente estudo envolve a injeção de substâncias esclerosantes no palato mole para o tratamento das roncopatias. Realizamos a comparação de duas substâncias para este procedimento: o etanol $50 \%$ e o oleato de etanolamina $5 \%$.

Não sabemos se os resultados e as possíveis complicações da injeção roncoplástica dependem do tipo de substância utilizada e da metodologia de aplicação empregada. A carência de algumas respostas sobre este tipo de tratamento nos motivou a elaborar esta pesquisa. 
2 OBJETIVOS 


\section{OBJETIVOS}

O objetivo principal deste estudo é analisar os resultados da injeção roncoplástica no tratamento do ronco, comparando duas substâncias: o etanol $50 \%$ e o oleato de etanolamina $5 \%$. A variável de desfecho principal é a intensidade do ronco, medida em escala visual analógica (EVA) de $10 \mathrm{~cm}$.

Os objetivos secundários do estudo são:

a) Descrever nossa própria metodologia de aplicação para analisar seus resultados clínicos e suas possíveis complicações;

b) Comparar as medidas palatais por ressonância magnética antes e após as injeções;

c) Comparar os resultados polissonográficos antes e após os procedimentos. 
3 REVISÃO DA LITERATURA 


\section{REVISÃO DA LITERATURA}

De acordo com Chao e Ayub (2004), a história da escleroterapia se iniciou no século IV a.C. quando Hipócrates utilizou ferro em brasa para cauterizar um vaso sangrante de um paciente. Em 1667, Elsholt utilizou uma solução esclerosante de tanchagem (Plantago major) para tratar uma úlcera de um soldado. Após o advento da seringa hipodérmica desenvolvida por Pravatz, em 1851, Soquet e Guilhermond realizaram escleroterapia com soluções iodadas, em 1854. Schiassi, em 1905, desenvolveu uma técnica própria para escleroterapia de varizes e foi um dos grandes responsáveis pela divulgação deste método (Chao, Ayub, 2004).

Os agentes esclerosantes podem ser divididos em três tipos, de acordo com seu mecanismo de ação: detergente, osmótico ou irritante. As substâncias utilizadas em nosso estudo já são conhecidas na medicina há muitas décadas, especialmente no tratamento de varizes. $\mathrm{O}$ uso do etanol absoluto para escleroterapia vascular foi descrito no início do século XIX por Monteggio e posteriormente por Leroy D'Etiolles. Trata-se de um agente esclerosante com mecanismo de ação osmótico. O oleato de etanolamina introduzido por Biegeleisen, em 1937, é um esclerosante de alta viscosidade com mecanismo de ação detergente. Estes dois agentes são utilizados na medicina há décadas para vários tipos de escleroterapia: telangiectasias, malformações vasculares e linfáticas, cistos, varizes, dentre outras. Em casos de varizes esofágicas, são utilizadas altas doses do agente 
esclerosante, até $20 \mathrm{~mL}$, com relativa segurança. As principais complicações do uso destes esclerosantes são: dor, edema, necrose tecidual e hiperpigmentação de pele. Reações alérgicas são raras, porém há relatos de complicações pulmonares e renais decorrentes do uso do oleato de etanolamina em altas doses. Complicações graves pelo uso de outros agentes esclerosantes já foram descritas: raros casos de anafilaxia e morte, potencialmente pelo uso de altas doses de tetradecil sulfato de sódio em pacientes com varizes esofágicas decorrentes de falência hepática e hipertensão portal (Levinson, 2001; Chao, Ayub, 2004; Feied, 2007).

Apesar da escleroterapia vascular ser realizada há séculos, Strauss (1943) foi o primeiro a executar uma escleroterapia para o tratamento do ronco. Publicou uma pequena série de casos com sete pacientes, que receberam injeções de psiliato de sódio $\left(\right.$ Sylnaso $\left.{ }^{\circledR}\right)$, uma droga esclerosante com ação irritativa. As aplicações foram feitas no palato mole e nos pilares tonsilares. Observou o desaparecimento do ronco em um paciente e melhora importante do ronco em três pacientes.

Em 1998, Powell et al. realizaram estudo em 22 pacientes roncadores com IAH menor do que 15 por hora. Tais indivíduos foram submetidos a sessões de radiofrequência no palato mole. Além da melhora clínica do ronco em escala visual analógica (EVA) de $8,3 \pm 1,8$ para $1,9 \pm 1,7(p=0,0001)$, os autores também observaram por meio de cefalometria que houve redução do comprimento do palato mole, com encurtamento de $5,5 \pm 3,7 \mathrm{~mm}$ $(p<0,0001)$.

Após a publicação de Strauss (1943), não ocorreram estudos 
subsequentes sobre escleroterapia palatal até que Brietzke e Mair (2001) publicaram um estudo alentador utilizando tetradecil sulfato de sódio $\left(\right.$ Sotradecol $\left.{ }^{\circledR}\right)$, um agente esclerosante consagrado para tratamento de veias varicosas e telangiectasias. Injetaram este agente no palato mole de humanos, $2 \mathrm{~mL}$ em único ponto, na linha média. Quando o ronco ainda incomodava, nova sessão era realizada com injeção de mais $2 \mathrm{~mL}$ lateralmente à área de fibrose palatal prévia. Os autores realizavam até três sessões por paciente, com intervalo de seis a oito semanas. Mostraram excelentes resultados clínicos para tratamento do ronco primário: 92\% de sucesso após 12 meses de acompanhamento.

Lopes et al. (2002) realizaram estudo experimental injetando oleato de etanolamina (Ethamolin ${ }^{\circledR}$ ) na base da língua de suínos. A língua destes animais é muito semelhante à de humanos, principalmente na sua espessura. Fizeram análise histológica posterior dos locais de injeção e observaram compactação e espessamento do colágeno, com formação de fibrose tecidual, significativamente aumentada em relação aos controles.

Em 2003, Brietzke e Mair publicaram um novo estudo no qual aumentaram a casuística para 42 pacientes e o tempo de seguimento: em 19 meses a taxa de sucesso inicial diminuiu para $75 \%$. Neste estudo, descreveram ainda um caso de fístula palatal resultante da aplicação de tetradecil sulfato de sódio a 3\%.

Em 2004, Brietzke e Mair desenvolveram um estudo comparativo entre diferentes tipos de substâncias esclerosantes para o tratamento do ronco. Observaram que o etanol $50 \%$ foi o que apresentou eficácia mais 
semelhante ao tetradecil sulfato de sódio. No entanto, o etanol mostrou potencial discretamente maior para algumas complicações, como dor e fístula. Entretanto, este risco de fístula palatal é maior se o etanol for utilizado em sua concentração máxima, ou seja, álcool absoluto (Brietzke, Mair, 2004).

Iseri e Balcioglu (2005) compararam a escleroterapia com a radiofrequência (RF), ambas no palato mole de indivíduos roncadores. Utilizaram injeções de polidocanol, um agente com ação detergente. Após seis semanas, observaram sucesso em $87,5 \%$ dos pacientes que realizaram a $\mathrm{RF}$ e em $76,7 \%$ daqueles submetidos à escleroterapia. Os níveis de desconforto foram similares nos dois grupos.

Em 2006, Poyrazoglu et al. realizaram análise histológica em palato mole de ratos submetidos a escleroterapia e RF. Notaram que ambos procedimentos provocaram um endurecimento do palato, com fibrose e queratinização. Entretanto, este efeito ocorreu de maneira um pouco mais intensa com a escleroterapia.

Em 2008, Lorenzetti et al. propuseram o termo Injeção Roncoplástica (IR) para designar a escleroterapia do palato mole com objetivo de tratar o ronco e os distúrbios respiratórios do sono, por injeção intersticial de substâncias esclerosantes. Acredita-se que este termo "Injeção Roncoplástica" seja o mais adequado para designar este procedimento, evitando confusões com outros tipos de escleroterapia. Desta forma, além de ser distinto e auto-explicativo, o termo Injeção Roncoplástica se assemelha ao existente em inglês: "Injection Snoreplasty". 
Al-Jassim e Lesser (2008) executaram injeção palatal de tetradecil sulfato de sódio em pacientes roncadores. Notaram que, com apenas uma sessão, $62 \%$ dos pacientes apresentaram melhora importante do ronco num curto prazo. Neste estudo, os autores também sugeriram que este procedimento poderia ser usado não apenas para o tratamento do ronco, mas também para investigar quais pacientes seriam bons candidatos para cirurgia palatal. 
4 CASUÍSTICA E MÉTODOS 


\section{CASUÍSTICA E MÉTODOS}

\subsection{Casuística}

O estudo intervencional, duplo-cego e randomizado foi realizado com 22 pacientes do Ambulatório de Ronco da Disciplina de Otorrinolaringologia do Hospital das Clínicas da Faculdade de Medicina da Universidade de São Paulo (HCFMUSP), no período de janeiro de 2007 até agosto de 2010.

A pesquisa foi aprovada previamente pela Comissão de Ética para Análise de Projetos de Pesquisa (CAPPesq) da Diretoria Clínica do HCFMUSP, protocolo número 508/05 (Apêndice 1). Os pacientes foram convidados a participar do estudo e assinaram o Termo de Consentimento Livre e Esclarecido (Apêndice 2).

\subsubsection{Critérios de inclusão}

Eram elegíveis para o estudo adultos de ambos os gêneros com ronco de alta intensidade como queixa principal e cujo exame polissonográfico evidenciasse IAH entre zero e 15 eventos por hora de sono.

\subsubsection{Critérios de exclusão}

Foram excluídos pacientes que apresentassem qualquer uma das 
condições ou situações seguintes: 1) história de cirurgia prévia para tratamento de ronco ou SAOS; 2) índice de massa corpórea (IMC) acima de 35; 3) obstrução anatômica nasal ou faríngea superior a 50\% da luz; 4) deformidade crânio-facial; 5) gestantes; 6) doenças graves associadas (ASA III e IV); 7) história de alergia à lidocaína, etanol ou etanolamina e 8) ausência de acompanhante para observar a intensidade do ronco.

\subsection{Métodos}

Cada paciente era alocado, de maneira aleatória com auxílio de uma moeda, em um de dois grupos: se o resultado do sorteio fosse cara, o paciente ingressava no Grupo A, se fosse coroa, no Grupo B. Os pacientes do Grupo A receberam oleato de etanolamina 5\% (solução A), e os do Grupo B etanol a $50 \%$ (solução B). Todos os pacientes foram submetidos a uma, duas ou no máximo três sessões, com intervalo mínimo de quatro semanas, sempre com a mesma droga (solução A ou B).

As soluções foram previamente preparadas em seringas identificadas apenas como solução $A$ ou $B$, e este preparo feito por um médico que não participou do restante do estudo. O preparo foi realizado alguns minutos antes das aplicações, da maneira seguinte:

- Solução identificada como A: em uma seringa estéril de $3 \mathrm{~mL}$ foi aspirado $1,5 \mathrm{~mL}$ de oleato de etanolamina $5 \%$ (marca 
Ethamolin ${ }^{\circledR}$, fabricado pelo laboratório Zest em ampolas de $2 \mathrm{~mL})$;

- Solução identificada como B: em uma seringa estéril de $3 \mathrm{~mL}$ foi aspirado $1 \mathrm{~mL}$ de etanol $99,5 \%$ (fabricado pela farmácia do HCFMUSP em ampolas de $10 \mathrm{~mL}$ ) diluído com $1 \mathrm{~mL}$ de lidocaína 2\% (sem adrenalina, marca Xylestesin ${ }^{\circledR}$, fabricada pelo laboratório Cristália). Após a mistura, foram desprezados $0,5 \mathrm{~mL}$ da solução, preservando $1,5 \mathrm{~mL}$ na seringa;

Para as injeções foram utilizadas seringas estéreis de $3 \mathrm{~mL}$ descartáveis, marca Injex ${ }^{\circledR}$, agulhas estéreis e descartáveis de Abbocath $^{\circledR}$ número $24 \mathrm{G}$, além de luvas estéreis tamanho médio, marca Bioservice ${ }^{\circledR} \mathrm{e}$ abaixadores de língua descartáveis. Os principais materiais utilizados para o procedimento estão ilustrados na Figura 1. A iluminação foi realizada com fotóforo, marca Welch Allyn ${ }^{\circledR}$, com lâmpada frontal de estado sólido, modelo 49020.

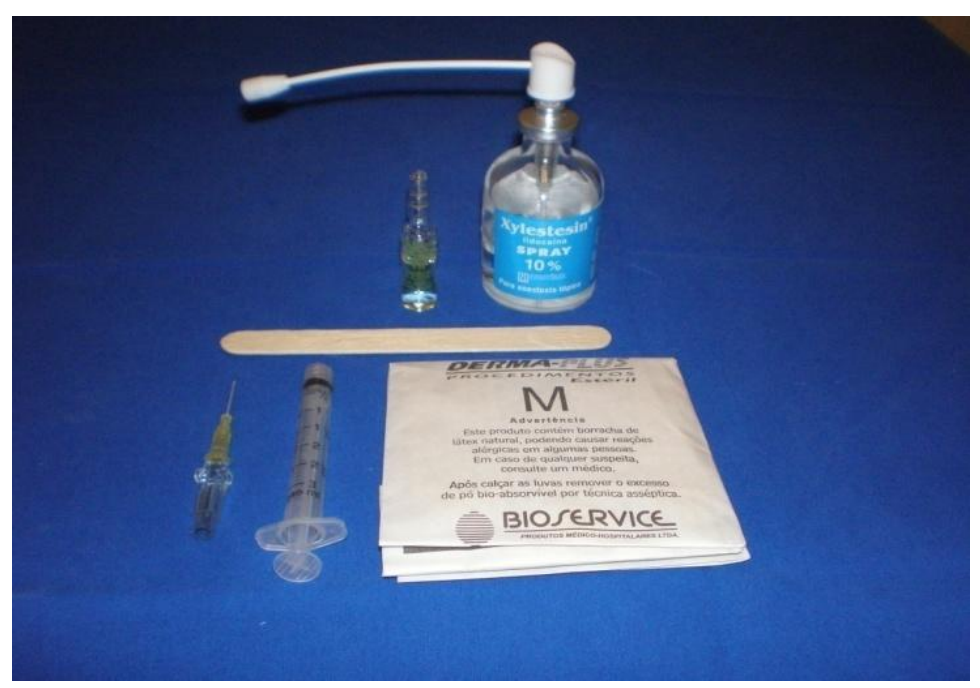

Figura 1 - Material utilizado para a injeção roncoplástica. 
Para a anestesia tópica foram aplicados três jatos de lidocaína spray $10 \%$ (marca Xylestesin ${ }^{\circledR}$, fabricado pelo laboratório Cristália) no palato mole dos pacientes, e, em seguida, foi solicitado que deglutissem o anestésico. Após dois minutos, foram injetados $1,5 \mathrm{~mL}$ de solução (A ou B) em cada sessão. A aplicação ocorreu em três pontos distintos do palato mole $(0,5 \mathrm{~mL}$ em cada ponto): uma injeção mediana e duas para-medianas, como mostram as Figuras 2 e 3.

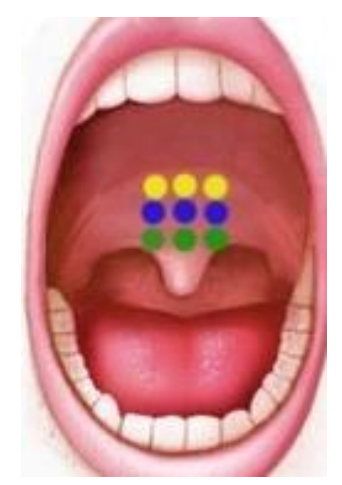

Figura 2 - Esquema simplificado das áreas de injeção: na primeira sessão (azul), na segunda sessão (verde) e na terceira sessão (amarela).

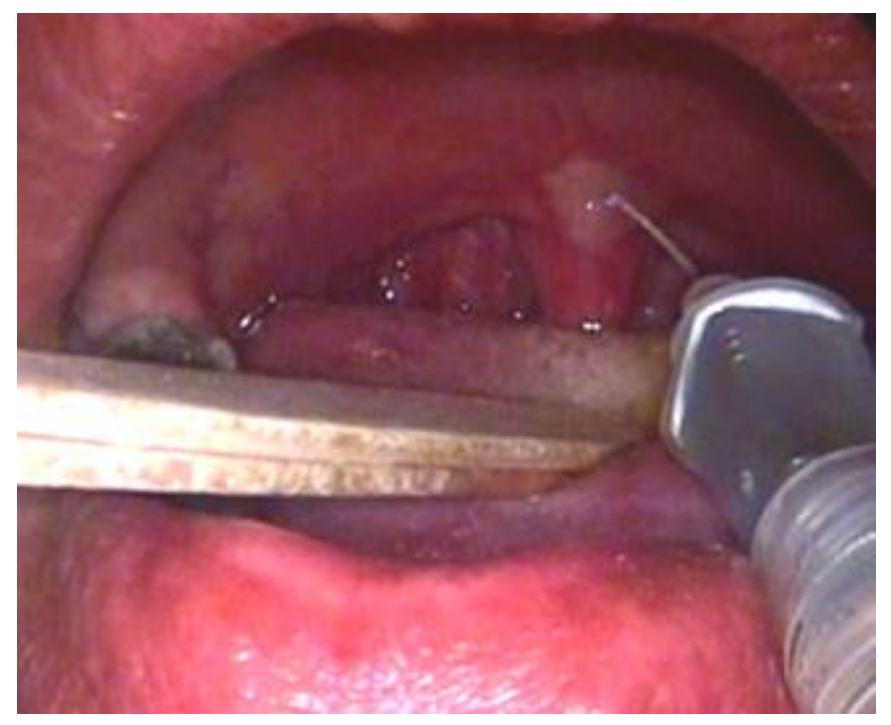

Figura 3 - Injeção palatal da substância esclerosante, na linha média. 
A substância era injetada preferencialmente na camada submucosa do palato mole, e para isso era introduzido apenas o bisel da agulha, com inclinação de aproximadamente 45 graus. Em seguida, era observada a formação de uma bolha em cada local de injeção, as quais ficavam menos evidentes à medida que o agente esclerosante se difundia e o palato tornava-se edemaciado. Após a aplicação, o paciente permanecia em observação por um período mínimo de 30 minutos. Depois disso, era liberado e orientado a ingerir dieta fria, preferencialmente líquida ou pastosa, enquanto o palato estivesse dolorido ou edemaciado. Era prescrito: analgésico (Dipirona 500mg, da farmácia do HCFMUSP) via oral, enquanto necessário, na dose de um comprimido a cada seis horas; spray oral de hexamidina com tetracaína (marca Hexomedine ${ }^{\circledR}$, fabricado pelo laboratório Sanofi-Aventis) - dois jatos no palato mole até de quatro em quatro horas, se tivesse dor; além disso, higiene oral e gargarejos com solução bucal sem álcool a base de clorexidina a $0,12 \%$ (marca Periogard ${ }^{\circledR}$, fabricado por Colgate) duas vezes ao dia.

Os retornos ocorriam semanalmente até a cicatrização palatal completa. Se após quatro semanas do procedimento o ronco ainda continuasse incomodando o(a) parceiro(a), o procedimento era repetido utilizando a mesma droga (A ou B) da primeira sessão.

Foram realizadas análises clínicas, questionários, exame físico otorrinolaringológico, nasofibrolaringoscopia com manobra de Mueller, ressonância magnética (RM) e polissonografia (PSG). O médico que realizou as aplicações e avaliou os resultados, assim como os pacientes e 
acompanhantes, não sabiam qual droga era utilizada. Todas as avaliações foram realizadas antes do primeiro procedimento e três meses após a última aplicação. Depois da realização de todos os exames, os pacientes foram acompanhados em ambulatório com retornos trimestrais por um período mínimo de 12 meses.

\subsubsection{Avaliação clínica}

Os parâmetros clínicos analisados foram semelhantes aos que Cahali (2002) utilizou em sua tese de doutorado:

- Verificação da massa corpórea dos pacientes em balança de plataforma (medida em quilogramas, com a pessoa usando roupas leves e sem sapatos; do IMC (calculado pela massa do indivíduo dividida pelo quadrado de sua altura, em $\mathrm{kg} / \mathrm{m}^{2}$, e a altura foi medida com o medidor da mesma balança de plataforma, de modo que o esquadro tocasse o topo do crânio, comprimindo o cabelo).

- Os pacientes preencheram a Escala de Sonolência de Epworth (Johns, 1991); Esta escala varia de zero a 24 pontos e está ilustrada no Quadro 1; 
Quadro1 - Escala de sonolência de Epworth.

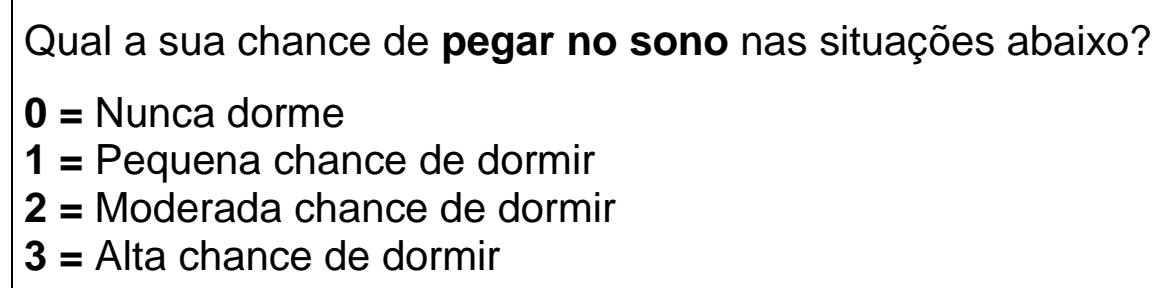

\begin{tabular}{|l|l|}
\hline SITUAÇÕES: & NOTA \\
\hline Sentado e lendo & \\
\hline Assistindo televisão & \\
\hline Sentado, sem fazer nada, num local público & \\
\hline $\begin{array}{l}\text { Como passageiro num carro andando por uma hora sem } \\
\text { parar }\end{array}$ & \\
\hline Deitando-se à tarde (quando pode) & \\
\hline Sentado e conversando com alguém & \\
\hline $\begin{array}{l}\text { Sentado, quieto, depois de um almoço sem bebida } \\
\text { alcoólica }\end{array}$ & \\
\hline $\begin{array}{l}\text { Num carro, enquanto parado por alguns minutos no } \\
\text { trânsito }\end{array}$ & \\
\hline
\end{tabular}

- Com o auxílio do(a) parceiro(a) de quarto, os pacientes preencheram os questionários com escalas visuais analógicas (EVA) de $10 \mathrm{~cm}$, destinados a quantificar a intensidade dos roncos. Além disso, preenchimento de a questão: após quantos dias a intensidade do ronco melhorou?

- Para avaliar a porcentagem de sucesso deste tratamento para o ronco, foram utilizados os mesmos critérios subjetivos propostos por Brietzke e Mair, em 2001: desaparecimento ou melhora significativa do ronco, a ponto de não incomodar mais o(a) parceiro(a). 
- Avaliação pelos pacientes sobre a dor no momento da injeção e nos primeiros dias após a injeção, utilizando EVA de $10 \mathrm{~cm}$. Além destas questões, também foi respondida a pergunta: após quantos dias voltou a se alimentar normalmente?

\subsubsection{Exame otorrinolaringológico}

Durante o exame físico otorrinolaringológico foi dispensada uma atenção especial para os parâmetros (Friedman et al., 2004; Zonato, 2010) seguintes:

4.2.2.1 Graduação do tamanho das tonsilas palatinas

As tonsilas palatinas foram graduadas de zero a quatro, pelos critérios seguintes:

- Grau 0: tonsilas ausentes;

- Grau 1: tonsilas ocupam até $25 \%$ do espaço orofaríngeo;

- Grau 2: tonsilas ocupam entre $25 \%$ e $50 \%$ do espaço orofaríngeo;

- Grau 3: tonsilas ocupam entre 50 e $75 \%$ do espaço orofaríngeo;

- Grau 4: tonsilas ocupam mais de $75 \%$ do espaço orofaríngeo.

\subsubsection{Relação entre o palato mole e a língua}

Esta relação foi avaliada por meio da Classificação de Mallampati modificada por Friedman et al. (2004), na qual o paciente permanece com a língua relaxada dentro da cavidade bucal durante a oroscopia. Pode-se 
classificar esta posição palatal em relação à língua, mediante os critérios seguintes:

- Classe I: visualiza-se toda a parede posterior da orofaringe, tonsilas palatinas, pilares e úvula;

- Classe II: visualiza-se a úvula, totalmente ou parcialmente, o palato mole, uma pequena porção da parede faríngea posterior e apenas os pólos superiores das tonsilas;

- Classe III: visualiza-se totalmente o palato duro e parcialmente o palato mole;

- Classe IV: visualiza-se apenas o palato duro.

\subsubsection{Estadiamento de Friedman}

Associa os dois itens anteriores com o IMC dos pacientes. O Quadro 2 ilustra o sistema de estadiamento proposto (Friedman et al., 2004).

Quadro 2 - Sistema de Estadiamento de Friedman

\begin{tabular}{|l|c|c|c|}
\hline Estádio & $\begin{array}{c}\text { Mallampati } \\
\text { modificado }\end{array}$ & $\begin{array}{c}\text { Tonsilas } \\
\text { palatinas }\end{array}$ & $\begin{array}{c}\text { IMC } \\
\mathbf{( k g / \mathbf { m } ^ { 2 } )}\end{array}$ \\
\hline I & I ou II & 3 ou 4 & $<40$ \\
\hline II & I ou II & 0,1 ou 2 & $<40$ \\
& III ou IV & 3 ou 4 & $<40$ \\
\hline III & III ou IV & 0,1 ou 2 & $<40$ \\
\hline IV & I, II, III ou IV & $0,1,2,3$ ou 4 & $>40$ \\
\hline
\end{tabular}

$\overline{\mathrm{MC}}=$ i índice de massa corpórea 


\subsubsection{Nasofibrolaringoscopia}

Os exames de nasofibrolaringoscopia foram realizados antes e três meses após o término do tratamento, sob anestesia tópica nasal com lidocaína 2\% (marca Xylestesin, fabricada pela Cristália) pulverizada em spray, dois jatos em cada fossa nasal. O aparelho flexível utilizado foi da marca Olympus, com 3,4mm de diâmetro, modelo ENF-P4, acoplado à fonte de luz halógena de 250W da marca Ferrari. Os exames foram realizados sempre pelo mesmo examinador, no ambulatório de otorrinolaringologia do HCFMUSP. Durante os exames pré-tratamento, o examinador procurou possíveis alterações anatômicas em vias aéreas superiores que pudessem ter relação como o ronco e a SAOS, observou se havia alguma obstrução anatômica importante e executou a manobra de Mueller. Nos exames póstratamento, o examinador notou se havia alguma alteração em relação ao exame inicial e realizou novamente a manobra de Mueller (Borowiecki, Sassin, 1983; Ferreira, Pinto, 2010).

\subsubsection{Ressonância magnética}

Os exames de ressonância magnética foram realizados em aparelho de campo fechado, marca General Electric de 1,5T. Em todos os pacientes foi utilizada bobina neurovascular. Sequências com imagens sagitais e axias ponderadas em T1 e T2 foram obtidas na região da faringe. A espessura de 
corte foi de $3 \mathrm{~mm}$ com espaçamento de $0,5 \mathrm{~mm}$ e o campo de visão utilizado foi de $22 \mathrm{~cm}$.

Durante o exame os pacientes se mantiveram acordados e foram orientados a respirar suavemente pelo nariz. As imagens obtidas foram enviadas a uma estação de trabalho AW (General Electric). As aferições foram realizadas na imagem sagital mediana, na qual se pode observar a rafe mediana da língua e o maior diâmetro crânio-caudal do palato mole, incluindo a úvula. Foram realizadas as medidas seguintes:

- Comprimento crânio-caudal do palato mole: distância da espinha nasal posterior até a extremidade distal da úvula. A Figura 4 ilustra esta medida.

- Espessura ântero-posterior do palato mole: distância entre as margens anterior e posterior do palato mole, medida no ponto médio entre a espinha nasal posterior e a extremidade distal da úvula. Esta medida está exemplificada na Figura 4.

- Área do palato mole: após a delimitação de todo o contorno do palato mole, feita visualmente pelo radiologista, a área foi calculada pelo programa da estação de trabalho AW. A Figura 5 exibe como a área foi delimitada. 




Figura 4 - Corte sagital mediano de RM. A linha amarela mostra o comprimento crâniocaudal do palato mole, enquanto a linha vermelha exibe a espessura ânteroposterior do palato mole.

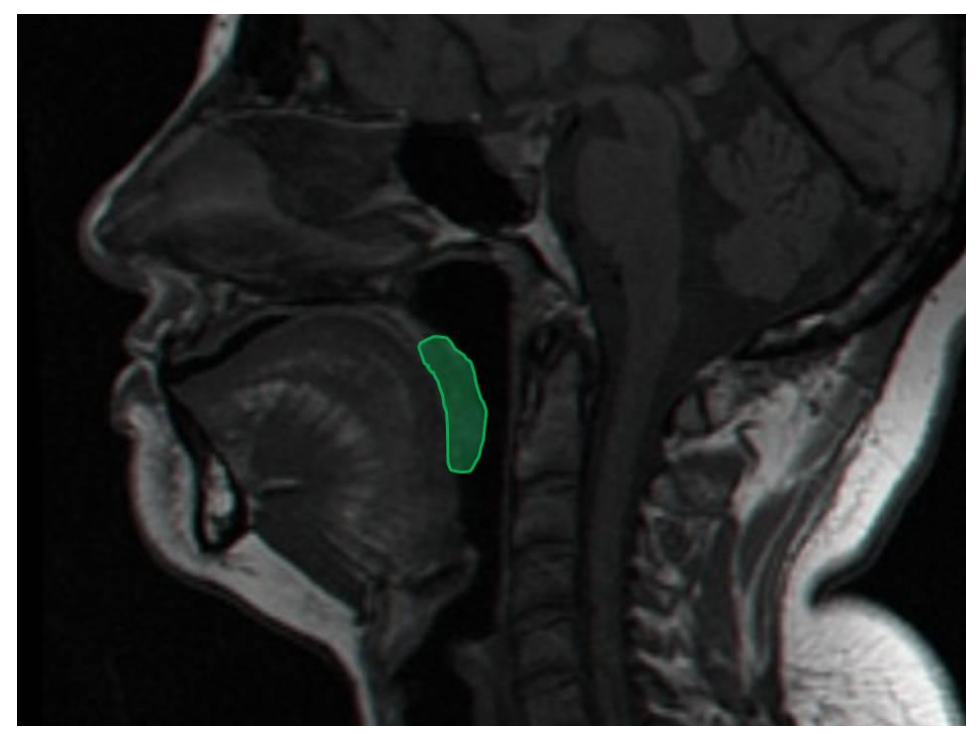

Figura 5 - Corte sagital mediano de RM, onde todo o contorno do palato mole foi delimitado em verde, para cálculo da área palatal. 
Um radiologista experiente fez a análise de todas as medidas de RM. Este profissional não teve contato com os pacientes, não sabia qual substância foi utilizada e nem mesmo o resultado clínico do tratamento (Daniel, 2003; Stuck, Maurer, 2009).

\subsubsection{Polissonografia}

As polissonografias foram realizadas antes e após o procedimento, no mesmo Laboratório do Sono e de acordo com as normas do manual da Academia Americana de Medicina do Sono: Seis canais de eletroencefalografia, eletrooculografia direita e esquerda, eletromiografia de mento e de membros inferiores, parâmetros de fluxo aéreo pela cânula e pelo termístor, esforço respiratório por cintas torácica e abdominal, saturação da oxihemoglobina por oxímetro de pulso, eletrocardiografia e sensor de posição corporal (Iber et al., 2007).

Durante as noites de exame, os pacientes dormiram no Laboratório do Sono, monitorizados com polígrafo Embla modelo S4000, sob supervisão de profissional habilitado.

A leitura dos exames e os laudos foram realizados por médico experiente na área de medicina do sono, e o mesmo não sabia qual substância foi utilizada e nem a opinião dos pacientes e acompanhantes sobre o tratamento. 


\subsection{Análise estatística}

Os dados coletados foram armazenados em um banco de dados e analisados utilizando-se o software SPSS for Mac versão 16.0 (SPSS Inc Chicago, IL). Dados categóricos (gênero, Mallampati, tonsilas palatinas, Friedman, sucesso segundo Brietzke e Mair, e prevalência de ulcerações em mucosa) foram comparados entre os grupos utilizando-se o teste do Quiquadrado e o teste Exato de Fisher e apresentados como n (\%). Variáveis contínuas foram testadas para normalidade utilizando-se o teste de Kolmogorov-Smirnof. Variáveis com distribuição normal e homogeneidade de variâncias (idade, IMC e Nadir $\mathrm{SO}_{2}$ ) foram sumarizadas através de média \pm desvio padrão e comparadas entre os grupos utilizando-se o teste $t$ de Student para amostras independentes, e entre os momentos pré e pós aplicação utilizando-se o teste t de Student para amostras pareadas. Dados ordinais, assim como dados contínuos que não apresentaram distribuição normal (nota para o ronco pela EVA, escore na escala de Epworth, IAH, número de microdespertares, dor na aplicação e na primeira semana, dias para alimentação normal, dias para a melhora do ronco e medidas palatais de RM), foram sumarizados como mediana e intervalo interquartil (percentil25-percentil75), comparados entre os grupos utilizando-se o teste $U$ de Mann-Whitney, e entre os momentos pré e pós aplicação utilizando-se o teste de Wilcoxon. Foram consideradas diferenças estatisticamente significantes quando os valores de $p$ foram menores ou iguais a 0,05 . 


\section{RESULTADOS}




\section{RESULTADOS}

Vinte e dois pacientes foram incluídos no protocolo, quatro do gênero masculino e 18 do gênero feminino. Deste total, nove pacientes foram alocados no grupo A (oleato de etanolamina) e 13 no grupo B (etanol 50\%).

A Tabela 1 apresenta os dados demográficos e referentes ao exame otorrinolaringológico. Todos os pacientes tiveram seguimento mínimo de 12 meses após o procedimento. Não houve diferença estatisticamente significante entre os grupos em relação ao gênero, idade, IMC e características da orofaringe pré-tratamento. 
Tabela 1 - Dados demográficos e referentes ao exame otorrinolaringológico.

\begin{tabular}{|c|c|c|c|c|}
\hline & \multicolumn{2}{|c|}{ Grupo } & \multirow[b]{2}{*}{$\mathbf{p}$} & \multirow[b]{2}{*}{$\begin{array}{l}\text { Total } \\
(\mathrm{n}=22)\end{array}$} \\
\hline & $\begin{array}{c}\mathbf{A} \\
\text { Oleato de } \\
\text { Etanolamina } \\
(\mathrm{n}=9)\end{array}$ & $\begin{array}{c}\mathbf{B} \\
\text { Etanol } \\
(n=13)\end{array}$ & & \\
\hline \multicolumn{5}{|l|}{ Gênero } \\
\hline Masculino & $1(11,1 \%)$ & $3(23,1 \%)$ & \multirow{2}{*}{0,62} & $4(18,2 \%)$ \\
\hline Feminino & $8(88,9 \%)$ & $10(76,9 \%)$ & & $18(81,8 \%)$ \\
\hline Idade (anos) & $49,7 \pm 12,6$ & $47,8 \pm 11,1$ & 0,71 & $48,5 \pm 11,5$ \\
\hline IMC & $25,1 \pm 2,5$ & $25,4 \pm 4,2$ & 0,79 & $25,3 \pm 3,6$ \\
\hline \multicolumn{5}{|l|}{ Mallampati } \\
\hline 1 & $1(11,1 \%)$ & $2(15,4 \%)$ & \multirow{3}{*}{0,57} & $3(13,6 \%)$ \\
\hline 2 & $4(44,4 \%)$ & $3(23,1 \%)$ & & $7(31,8 \%)$ \\
\hline 3 & $4(44,4 \%)$ & $8(61,5 \%)$ & & $12(54,5 \%)$ \\
\hline \multicolumn{5}{|l|}{ Tonsilas } \\
\hline 0 & $1(11,1 \%)$ & $1(7,7 \%)$ & \multirow{3}{*}{0,68} & $2(9,1 \%)$ \\
\hline 1 & $8(88,9 \%)$ & $11(84,6 \%)$ & & $19(86,4 \%)$ \\
\hline 2 & $0(0,0 \%)$ & $1(7,7 \%)$ & & $1(4,5 \%)$ \\
\hline \multicolumn{5}{|l|}{ Friedman } \\
\hline 2 & $5(55,6 \%)$ & $5(38,5 \%)$ & \multirow{2}{*}{0,67} & $10(45,5 \%)$ \\
\hline 3 & $4(44,4 \%)$ & $8(61,5 \%)$ & & $12(54,5 \%)$ \\
\hline
\end{tabular}

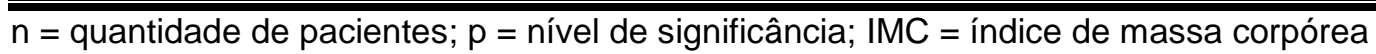

A maioria dos pacientes realizou três sessões de injeção de substância esclerosante. Seis pacientes $(66,7 \%)$ do grupo A e nove $(69,2 \%)$ pacientes do grupo B realizaram três sessões, enquanto que os restantes de ambos os grupos obtiveram resultado satisfatório já após a segunda sessão $(p=1,0)$. 
A Tabela 2 e a Figura 6 apresentam os escores medianos de intensidade do ronco medidos pelos pacientes (EVA) com auxílio dos companheiros de quarto. Para ambos os grupos houve redução estatisticamente significante no escore entre os momentos pré e pósaplicação. A redução média no escore de $5,3 \pm 1,7(p=0,007)$ no grupo $A$ (oleato de etanolamina) e 4,9 $\pm 1,9(p=0,001)$ no grupo $B$ (etanol).

Tabela 2 - Escores medianos de intensidade de ronco medidos em escala visual analógica.

\begin{tabular}{c|c|c|c}
\hline \hline \multirow{2}{*}{ Grupo } & \multicolumn{2}{|c|}{ Momento } & p \\
\cline { 2 - 3 } & Pré-aplicação & Pós-aplicação & \\
\hline A $(n=9)$ & $8,0(8,0-9,5)$ & $3,0(2,0-4,5)$ & 0,007 \\
B $(n=13)$ & $8,0(8,0-9,0)$ & $3,0(2,0-4,0)$ & 0,001 \\
Total $(n=22)$ & $8,0(8,0-9,0)$ & $3,0(2,0-4,0)$ & $<0,001$ \\
\hline \hline
\end{tabular}

Dados apresentados como mediana e intervalo interquartil (percentil 25 - percentil75); $p=$ nível de significância; $\mathrm{n}$ = quantidade de pacientes 


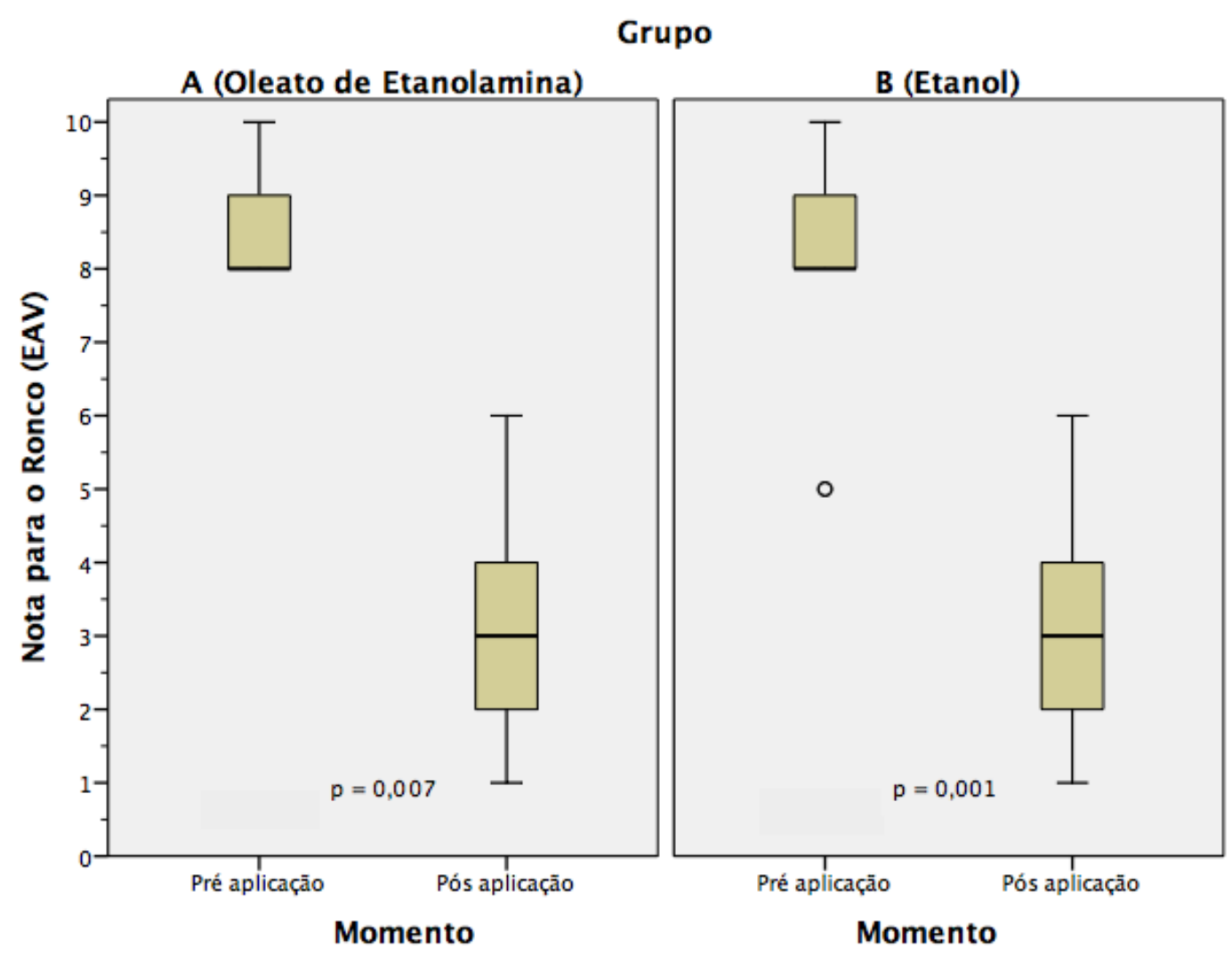

Figura 6 - Boxplot do escore de intensidade do ronco medido em escala visual analógica. Cada caixa apresenta a mediana (linha central) e o intervalo interquartil (percentil25-percentil75); valores mínimo e máximo são apresentados pelos whiskers ("bigodes"). ( $p$ = nível de significância)

Sete pacientes $(77,8 \%)$ do grupo A e 12 pacientes $(92,3 \%)$ do grupo B apresentaram sucesso no tratamento do ronco de acordo com os critérios propostos por Brietzke e Mair, e esta diferença entre os grupos não foi estatisticamente significante $(p=0,54)$.

A Tabela 3 apresenta as variações pré e pós-aplicação da substância esclerosante na escala de Epworth e para os parâmetros polissonográficos avaliados. Houve redução estatisticamente significante na escala de Epworth 
para ambos os grupos, e a diferença de maior magnitude no grupo B. Para os demais parâmetros polissonográficos não houve diferença estatisticamente significante entre os momentos.

Tabela 3 - Variações pré e pós-aplicação da substância esclerosante na escala de Epworth e para os parâmetros polissonográficos avaliados.

\begin{tabular}{|c|c|c|c|}
\hline & \multicolumn{2}{|c|}{ Momento } & \multirow{2}{*}{$\mathbf{p}$} \\
\hline & Pré-aplicação & Pós-aplicação & \\
\hline \multicolumn{4}{|l|}{ Grupo $A(n=9)$} \\
\hline Epworth & $8,0(3,0-14,5)$ & $6,0(4,0-7,5)$ & 0,05 \\
\hline $\mathrm{IAH}$ & $6,9(2,5-7,9)$ & $5,0(2,7-11,9)$ & 0,89 \\
\hline Nadir $\mathrm{SO}_{2}$ & $87,7 \pm 3,6$ & $88,4 \pm 4,2$ & 0,48 \\
\hline Microdespertares & $6,8(11,4-18,0)$ & $9,0(4,4-18,5)$ & 0,59 \\
\hline \multicolumn{4}{|l|}{ Grupo B $(n=13)$} \\
\hline Epworth & $11,0(5,0-14,5)$ & $5,0(3,0-10,0)$ & 0,005 \\
\hline $\mathrm{IAH}$ & $5,2(2,9-12,1)$ & $6,3(2,8-16,1)$ & 0,22 \\
\hline Nadir $\mathrm{SO}_{2}$ & $88,5 \pm 3,6$ & $87,7 \pm 4,7$ & 0,28 \\
\hline Microdespertares & $11,8(8,5-15,7)$ & $8,1(5,6-14,9)$ & 0,22 \\
\hline
\end{tabular}

Dados apresentados como mediana e intervalo interquartil (percentil25 - percentil75) ou média \pm desvio padrão; $p$ = nível de significância; $I A H$ = Índice de apneia-hipopneia; Nadir $\mathrm{SO}_{2}=$ Saturação mínima de $\mathrm{O}_{2}$

A Figura 7 apresenta a variação antes e após tratamento dos escores da nota do ronco e da escala de Epworth para os grupos A e B. Não houve diferença estatisticamente significante entre os grupos. 


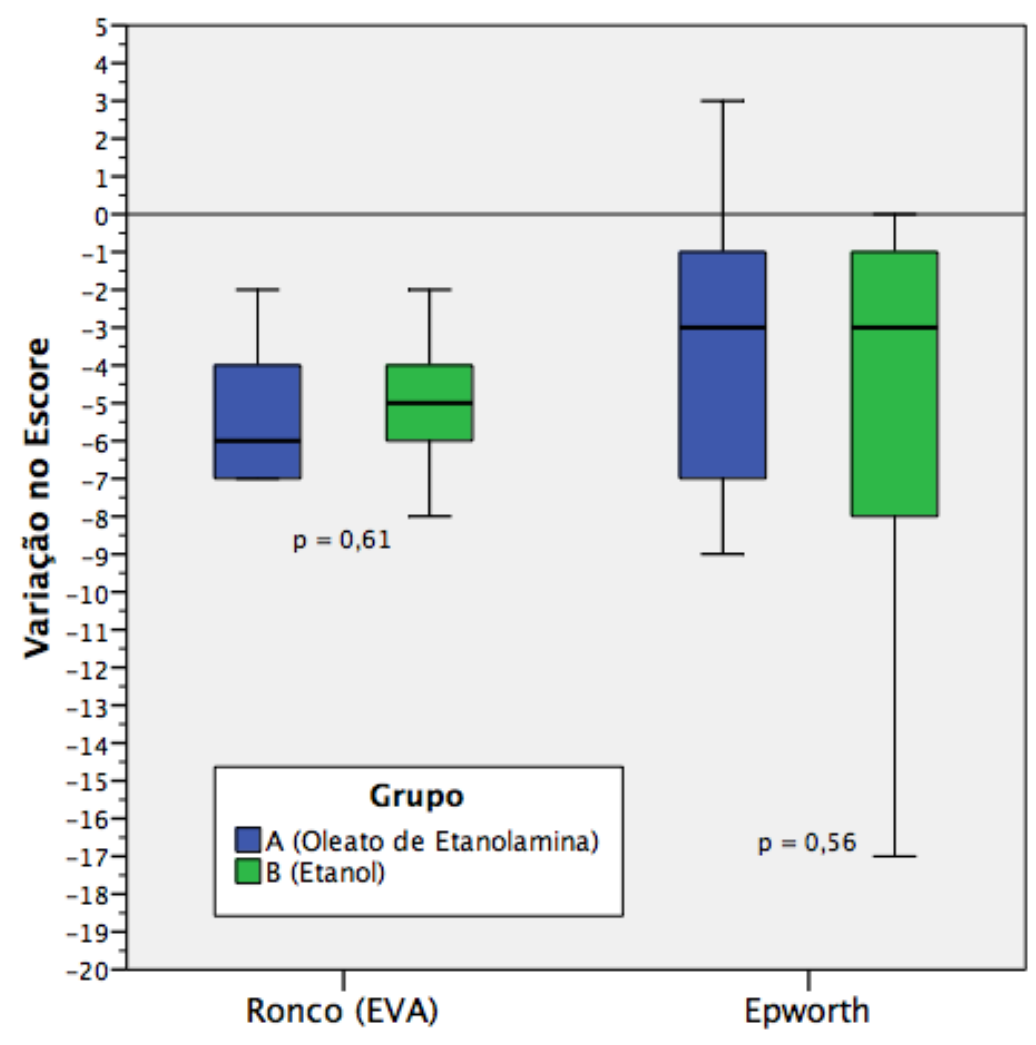

Figura 7 - Variação antes e após tratamento dos escores da nota do ronco e da escala de Epworth para os grupos A e B. ( $p=$ nível de significância; EVA = Escala visual analógica)

A Tabela 4 apresenta os aspectos relacionados à aplicação da substância esclerosante. Um total de 59 aplicações foram realizadas, 24 no grupo A e 35 no grupo B. Não houve diferença estatisticamente significante entre os grupos em relação à avaliação da dor durante a aplicação ou na primeira semana após a aplicação. Embora a ulceração no palato consequente à aplicação tenha ocorrido com maior frequência no grupo B - 
incidindo em todos os casos em que foi aplicado etanol contra $77,8 \%$ no grupo oleato de etanolamina - essa diferença não mostrou ser estatisticamente significante $(p=0,16)$.

Tabela 4 - Aspectos relacionados à aplicação da substância esclerosante.

\begin{tabular}{l|c|c|c|c}
\hline \hline & \multicolumn{2}{|c|}{ Grupo } & & \\
\cline { 2 - 3 } & $\begin{array}{c}\text { A } \\
\text { (Oleato de } \\
\text { Etanolamina) } \\
(\mathrm{n}=24)\end{array}$ & $\begin{array}{c}\text { B } \\
(\text { Etanol })\end{array}$ & $\mathbf{p}$ & Total \\
& \multicolumn{1}{|c|}{$(\mathrm{n}=35)$} & & $(\mathrm{n}=59)$ \\
\hline Dor & $4,0(2,0-6,8)$ & $4,0(2,0-5,0)$ & 0,93 & $4,0(2,0-5,0)$ \\
na aplicação & $3,5(1,3-7,5)$ & $2,0(1,0-3,0)$ & 0,36 & $3,0(2,0-5,0)$ \\
na primeira semana & $3,0(2,0-3,0)$ & $3,0(2,0-5,0)$ & 0,07 & $2,0(1,0-3,0)$ \\
Dias & $13,0(7,0-14,0)$ & $13,0(7,0-14,0)$ & 0,32 & $14,0(10,0-4,0)$ \\
até alimentação normal \\
para a melhora do ronco
\end{tabular}

Dados apresentados como mediana e intervalo interquartil (percentil25-percentil75); $\mathrm{n}=$ quantidade de pacientes; $p=$ nível de significância

As principais complicações transitórias observadas foram: dor no momento da injeção, desconforto nos primeiros dias após o procedimento, odinofagia, edema palatal, aftas rasas e ulcerações palatais mais profundas em alguns casos. A Figura 8 ilustra um caso do grupo B que apresentou ulceração palatal grande e seu processo de cicatrização. 

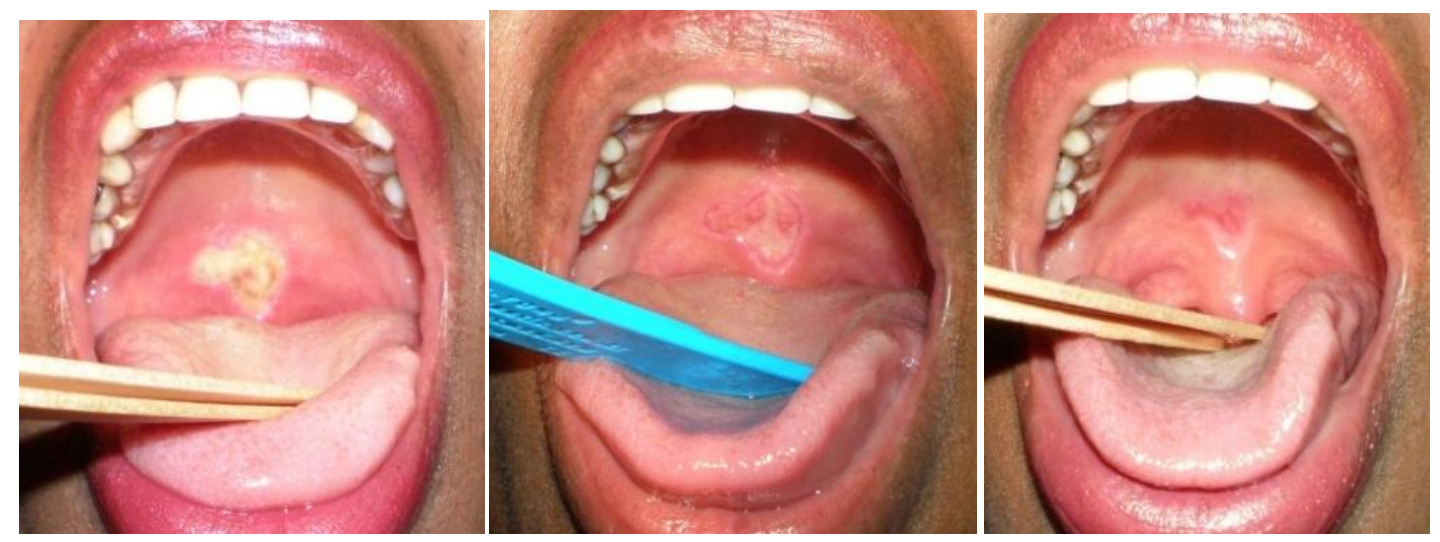

Figura 8 - Ulceração palatal grande após sete (imagem esquerda), 14 (imagem central) e 21 dias da injeção (imagem direita).

Todas estas complicações descritas foram resolvidas espontaneamente apenas com o tratamento padronizado descrito e as medidas de suporte. Empregando esta metodologia de aplicação, não observamos nenhum caso de fístula palatal.

Três pacientes do estudo, dois do grupo A e apenas um do grupo B, não fizeram nenhuma RM por claustrofobia. Outro paciente do grupo $A$, usuário de aparelho ortodôntico metálico, realizou a primeira RM a qual apresentou inúmeros artefatos que impossibilitaram a adequada medição dos parâmetros palatais. Assim, não foi submetido ao segundo exame.

Dezoito pacientes fizeram as RM antes e após o tratamento. Após o cálculo das medidas palatais, realizamos a comparação dos valores pré e pós-tratamento, independente de qual substância foi utilizada. A Tabela 5 ilustra os principais achados de RM. 
Tabela 5 - Medidas do palato mole encontradas na ressonância magnética.

\begin{tabular}{lccc}
\hline \hline $\begin{array}{l}\text { Pacientes submetidos } \\
\text { à RM } \\
(\mathbf{n = 1 8})\end{array}$ & $\begin{array}{c}\text { Antes do } \\
\text { Procedimento }\end{array}$ & $\begin{array}{c}\text { Após o } \\
\text { Procedimento }\end{array}$ & p \\
\hline Espessura palatal (AP) $(\mathrm{cm})$ & $0,9(0,8-0,9)$ & $0,8(0,7-0,9)$ & 0,34 \\
Comprimento palatal (CC) $(\mathrm{cm})$ & $3,7(3,3-3,9)$ & $3,4(3,2-3,7)$ & 0,02 \\
Área palatal $\left(\mathrm{cm}^{2}\right)$ & $2,8(2,4-3,3)$ & $2,6(2,4-3,0)$ & 0,29 \\
\hline \hline
\end{tabular}

$\overline{\text { Dados apresentados como mediana e intervalo interquartil (percentil25-percentil75); } \mathrm{n}=}$ quantidade de pacientes; $\mathrm{p}=$ nível de significância; $\mathrm{AP}=$ ântero-posterior; $\mathrm{CC}=$ crâniocaudal

Após a injeção roncoplástica houve redução em todas as medidas palatais analisadas na RM. Contudo, apenas o comprimento palatal teve uma redução estatisticamente significativa $(p=0,02)$. Esta redução do comprimento palatal foi de aproximadamente $0,3 \mathrm{~cm}$.

Os exames de nasofibrolaringoscopia antes e após as injeções não apresentaram nenhuma diferença relevante. O padrão de colabamento da faringe durante as manobras de Mueller também não sofreu modificações significantes.

Em todos os pacientes que apresentaram bons resultados no tratamento do ronco após três meses, este efeito se manteve durante todo o seguimento de 12 meses. 
6 DISCUSSÃO 


\section{DISCUSSÃO}

Nossos resultados apontaram que após duas ou três sessões de injeção roncoplástica houve melhora da intensidade do ronco e da escala de Epworth nos dois grupos, não havendo diferença estatística entre o grupo que recebeu oleato de etanolamina $5 \%$ e o que recebeu etanol $50 \%$. Os níveis de dor e desconforto também foram similares entre os grupos. Ulcerações e edema palatal ocorreram com frequência, porém não tivemos nenhum caso de fístula palatal. As variáveis polissonográficas e a nasofibroscopia não apresentaram variação antes e após o tratamento. Todas as medidas palatais por RM diminuíram após as injeções, mas apenas o comprimento palatal apresentou redução estatisticamente significativa.

Muitas vezes acreditamos que um tratamento é novo, mas, quando fazemos uma busca rigorosa na literatura, percebemos que alguém já teve a mesma idéia anteriormente. Isto ocorreu com a injeção roncoplástica: os principais estudos foram publicados por Brietzke e Mair no início do século XXI, porém, em 1943, Strauss já tivera a idéia de tratar o ronco com escleroterapia palatal. E como disse Friedrich Nietzsche "Logo que, numa inovação, nos mostram alguma coisa de antigo, ficamos sossegados".

O ronco é um problema que acomete grande parte da população e muitos destes indivíduos buscam uma solução simples e economicamente viável para tratar este problema. 
Existem várias alternativas disponíveis para tratar o ronco primário e a SAOS leve, mas a escolha do tratamento deve ser individualizada. Dentre as terapias conservadoras, podemos citar os aparelhos dentários de avanço mandibular e os geradores de fluxo aéreo. Por outro lado, diversas técnicas cirúrgicas que podem ser realizadas em ambiente hospitalar, sob anestesia geral: Uvulopalatofaringoplastia, Faringoplastia Lateral, Avanço MaxiloMandibular, dentre outras (Cahali, 2003; Robertson et al., 2008; Crespo et al., 2010).

Numa posição intermediária entre os tratamentos conservadores e as cirurgias citadas, existe um grupo de procedimentos cirúrgicos palatais que podem ser executados em ambulatório, sob anestesia local: Radiofrequência, LAUP e Implantes Palatais. Entretanto, tais tratamentos envolvem um custo relevante, usualmente superior a $\mathrm{R} \$ 1000,00$. Além destes, alguns estudos apontam que exercícios com a musculatura orofaríngea podem trazer algum benefício para pacientes com ronco e SAOS. Por outro lado, existem vários tratamentos alternativos para o ronco, geralmente sem grandes benefícios e sem evidências científicas, mas com forte apelo comercial (Savage, Steward, 2007; Guimarães et al., 2009; Crespo et al., 2010).

Desta maneira, procuramos estudar a injeção roncoplástica no Brasil por vários motivos: é uma técnica simples, de baixo custo e com risco aparentemente pequeno. Todas estas vantagens tornam este tratamento muito interessante para países com dificuldades econômicas. 
Nossos resultados mostraram uma concordância com a literatura: de acordo com os critérios estabelecidos por Brietzke e Mair (2001), a nossa taxa de sucesso na melhora do ronco foi de $86,4 \%$ na amostra geral, $77,8 \%$ no grupo que recebeu oleato de etanolamina e $92,3 \%$ no grupo que recebeu etanol. Todos os pacientes que tiveram melhora ou desaparecimento do ronco após três meses do tratamento mantiveram este sucesso ao longo dos 12 meses de seguimento, sugerindo que o efeito positivo da nossa técnica duraria, pelo menos, um ano.

Tais achados são condizentes com os principais estudos publicados: Brietzke e Mair (2001) tiveram 92\% de sucesso com seguimento de 12 meses, e no segundo estudo realizado por estes mesmos autores a amostra foi ampliada, o seguimento aumentou para 19 meses e a taxa de sucesso reduziu para 72\% (Brietzke, Mair, 2003). Em 2005, Iseri e Balcioglu encontraram sucesso em $76,7 \%$ dos pacientes, após seis semanas da última sessão de escleroterapia palatal para tratamento do ronco, enquanto AlJassim e Lesser (2008) tiveram 62\% de sucesso após três meses, com apenas uma sessão.

Em nossa casuística, o grupo submetido a injeções com etanol apresentou resultados discretamente melhores do que o grupo que recebeu o oleato de etanolamina. Porém não é possível afirmar que uma droga é superior a outra. Ambas apresentaram bons resultados e se mostraram seguras. Esta diferença clínica sutil nos resultados poderá se tornar mais evidente com o aumento da amostra e do tempo de seguimento. 
Uma das complicações mais temidas com este tratamento é a formação de fístula palatal. Em 2004, Brietzke e Mair descreveram uma taxa de $3 \%$ a $4 \%$ de fístula palatal, aplicando $2 \mathrm{~mL}$ da substância esclerosante num único ponto. Desta maneira, nossa idéia foi de aplicar uma quantidade menor, ou seja, $0,5 \mathrm{~mL}$ em três pontos distintos: acreditamos que desta maneira distribuímos melhor o agente, ampliamos a área de fibrose e reduzimos o risco de fístula palatal. Entretanto, com esta nossa modificação técnica, geralmente são necessárias duas ou três sessões para o efeito terapêutico pleno, enquanto com a técnica originalmente descrita por Brietzke e Mair (2001) este efeito pode ser obtido com sessão única, em alguns casos.

Uma limitação do estudo foi a amostra pequena e isto ocorreu por causa de várias dificuldades: critérios de seleção rigorosos, necessidade de vários retornos, exames subsidiários complexos e custos envolvidos. Além disso, alguns pacientes do gênero masculino não quiseram ingressar neste estudo alegando não ter tempo disponível para cumprir todo o protocolo. Isto fez com que a maioria dos pacientes estudados fosse do gênero feminino.

Pelo fato de realizarmos randomização simples com moeda, os grupos ficaram desiguais e isto prejudicou algumas avaliações. Como quatro pacientes, após ingressar no protocolo, não realizaram ou tiveram artefatos no exame de ressonância magnética, isto gerou uma desigualdade ainda maior: dos 18 pacientes que realizaram $\mathrm{RM}$ antes e após o procedimento, seis eram do Grupo A e 12 do grupo B. Desta forma, optamos por apenas 
analisar as medidas palatais antes e após o procedimento, independentemente da substância utilizada.

Em 1998, Powell et al. observaram uma redução do comprimento do palato mole após sessões de radiofrequência, por meio de análise cefalométrica. Stuck et al. (2005) realizaram ressonância magnética antes e após RF de base de língua. Não encontraram alterações nas medidas linguais dos pacientes estudados pela RM.

Nossos resultados de RM evidenciaram uma redução das medidas palatais após as injeções, e esta diminuição é estatisticamente significativa para o comprimento do palato mole. Este dado é inédito na literatura, pois não encontramos nenhuma publicação com exames de imagem antes e após sessões de injeção roncoplástica. Não sabíamos se a fibrose decorrente das injeções apenas enrijecia e reduzia a vibração do palato mole ou se também havia uma retração com diminuição do comprimento palatal. Nossos resultados apontam a favor desta segunda hipótese.

Os exames de nasofibrolaringoscopia com manobra de Mueller não apresentaram modificações significantes antes e após os procedimentos. Sua importância principal foi investigar se os pacientes do protocolo não apresentavam nenhuma obstrução anatômica nasal ou faríngea superior a $50 \%$ da luz antes do procedimento e certificar que não ficaram com sequelas após o tratamento.

Uma das maiores dificuldades encontradas no estudo foi quantificar a intensidade do ronco de uma maneira fidedigna. Apesar da PSG ser um exame bastante completo, o aparelho não é capaz de mensurar o ronco de 
uma maneira confiável, pois os sensores de ronco apresentam problemas e artefatos com frequência. Além disso, alguns pacientes roncam apenas em alguns períodos específicos da noite, como em posição supina ou em sono REM, dificultando ainda mais esta mensuração. Cathcart et al. (2010) realizaram análise acústica de 20 pacientes roncadores e constataram que existe uma variação natural da intensidade do ronco em noites consecutivas. Concluíram que analisar o ronco apenas uma noite não é um parâmetro confiável, são necessárias pelo menos quatro noites de análise para diminuir a margem de erro.

Pensamos em várias maneiras tornar esta quantificação da intensidade do ronco mais objetiva, porém, finalmente optamos pela avaliação em EVA feita com auxílio do(a) companheiro(a) de quarto, que costuma ser a pessoa mais prejudicada por causa do ronco. Nada adiantaria se tivéssemos uma medida objetiva que mostrasse melhora do ronco, mas que o(a) parceiro(a) de quarto tivesse uma opinião contrária.

Não encontramos nenhuma diferença estatisticamente significativa no IAH antes e depois do tratamento. Este resultado corrobora com a nossa visão de que a injeção roncoplástica é um tratamento destinado idealmente para pacientes com ronco primário.

Sabemos que o local envolvido com maior frequência na gênese do ronco é o palato mole. Portanto, quando existir um método fidedigno capaz de determinar quais são os pacientes cujo ronco é predominantemente palatal, possivelmente as taxas de sucesso da injeção roncoplástica poderão ser ainda melhores. Neste campo, existem alguns estudos com análise 
acústica do ronco e com sonoendoscopia, porém tais métodos ainda necessitam de maiores evidências para mostrar o seu valor como preditores de sucesso terapêutico (Brietzke, Mair, 2006; Jones et al., 2006; Berry, Whittet, 2009; Ferreira, Pinto, 2010; Cathcart et al., 2010)

Apesar dos bons resultados alcançados no presente estudo com a injeção roncoplástica, pretendemos aprofundar esta nossa linha de pesquisa para elucidar:

- Qual a melhor substância esclerosante?

- Qual a melhor metodologia de aplicação?

- Quem são os candidatos ideais para este procedimento?

- Existe uma maneira fidedigna de identificar os roncadores palatais?

- Quais as possíveis complicações da injeção?

- Quanto tempo dura o efeito do tratamento?

Da mesma maneira, encorajamos outros estudos de diferentes pesquisadores nesta área para esclarecer tais questões. 
7 CONCLUSÕES 


\section{CONCLUSÕES}

A injeção roncoplástica mostrou bons resultados no tratamento do ronco. A melhora na intensidade do ronco, em EVA, ocorreu nos dois grupos, porém não houve diferença estatística entre o grupo que recebeu etanol $50 \%$ e o grupo tratado com oleato de etanolamina $5 \%$.

A Escala de Sonolência de Epworth reduziu nos dois grupos, sem diferença estatística entre eles. Os níveis de dor durante a aplicação, assim como nos primeiros dias após a aplicação, foram similares entre os grupos. Também não houve diferença entre os grupos em relação ao tempo de retorno à alimentação normal e ao período para que houvesse melhora do ronco.

Nossa metodologia de aplicação, com injeção de um volume menor da droga em três pontos palatais distintos, reproduziu as taxas de sucesso da literatura, contudo, não tivemos casos de fístula palatal e nenhuma complicação grave.

As medidas palatais realizadas por RM mostraram que o comprimento palatal reduziu após as injeções. A espessura do palato mole e a área palatal não sofreram alterações estatisticamente significativas.

Os parâmetros polissonográficos analisados (IAH, Saturação mínima de $\mathrm{O}_{2}$ e Microdespertares) não sofreram alteração relevante após o tratamento. 
REFERÊNCIAS 


\section{REFERÊNCIAS 1}

Al-Jassim AH, Lesser THJ. Single dose injection snoreplasty: investigation or treatment? J Laryngol Otol. 2008;122(11):1190-3.

American Academy of Sleep Medicine. Sleep related breathing disorders in adults: recommendations for syndrome definition and measurements techniques in clinical research. Sleep. 1999;22(5):667-89.

Berry S, Whittet HB. Validity of sleep nasendoscopy in the investigation of sleep-related breathing disorder. In: Friedman M, editor. Sleep Apnea and Snoring. Surgical and Non-Surgical Therapy. $1^{\text {a }}$ ed. Chicago: Saunders Elsevier; 2009. p.42-4.

Borowiecki BD, Sassin JF. Surgical treatment of sleep apnea. Arch Otolaryngol. 1983;109(8):508-12.

${ }^{1}$ De acordo com:

Adaptado de International Committee of medical Journals Editors (Vancouver).

Universidade de São Paulo. Faculdade de Medicina. Serviço de biblioteca e Documentação. Estrutura e apresentação de dissertações e teses. Elaborado por Anneliese Carneiro da Cunha, Maria Julia A.L. Freddi, Maria F. Crestana, Marinalva de S. Aragão, Suely C. Cardoso, Valéria Vilhena. São Paulo, Serviço de biblioteca e Documentação, 1996.

Abreviaturas dos títulos dos periódicos de acordo com List of Journals Indexed in Index Medicus. 
Brietzke SE, Mair EA. Injection snoreplasty: how to treat snoring without all the pain and expense. Otolaryngol Head Neck Surg. 2001;124(5):503-10.

Brietzke SE, Mair EA. Injection snoreplasty: extended follow-up and new objective data. Otolaryngol Head Neck Surg. 2003; 128(5):605-15.

Brietzke SE, Mair EA. Injection snoreplasty: investigation of alternative sclerotherapy agents. Otolaryngol Head Neck Surg. 2004;130(1):47-57.

Brietzke SE, Mair EA. Acoustical analysis of snoring: Can the probability of success be predicted? Otolaryngol Head Neck Surg. 2006;135(3):417-20.

Brietzke SE, Mair EA. Injection snoreplasty. In: Friedman M, editor. Sleep Apnea and Snoring. Surgical and Non-Surgical Therapy. Chicago: Saunders Elsevier; 2009. p.165-8.

Cahali MB. Faringoplastia lateral versus uvulopalatofaringoplastia no tratamento da síndrome da apnéia e hipopnéia obstrutiva do sono [Tese]. São Paulo: Faculdade de Medicina, Universidade de São Paulo; 2002.

Cahali MB. Lateral Pharyngoplasty: A new treatment for obstructive sleep apnea hypopnea syndrome. Laryngoscope. 2003;113:1961-8. 
Cathcart RA, Hamilton DW, Drinnan MJ, Gibson GJ, Wilson JA. Night-tonight variation in snoring sound severity: one night studies are not reliable. Clin Otolaryngol. 2010;35(3): 198-203.

Chao S, Ayub MG. Escleroterapia. In: Maio M, editor. Tratado de Medicina Estética. São Paulo: Editora Roca; 2004. p.1573-7.

Crespo AN, Zancanella E, Carvalho EGB. Indicação e seleção do tratamento cirúrgico da SAOS. In: Pinto JA, editor. Ronco e Apneia do Sono. 2a ed. Rio de Janeiro: Revinter; 2010. p.141-58..

Daniel MM. Ressonância magnética na síndrome da apnéia obstrutiva do sono: características anatômicas das vias aéreas superiores relacionadas ao sexo [Tese]. São Paulo: Faculdade de Medicina, Universidade de São Paulo; 2003.

Feied, C. Sclerosing solutions. In: Bergan JJ, editor. The Vein Book. Oxford: Elsevier; 2007. p.125-32.

Ferreira RDP, Pinto JA. Nasofibrolaringoscopia e sonoendoscopia. In: Pinto JA, editor. Ronco e Apneia do Sono. $2^{\text {a }}$ ed. Rio de Janeiro: Revinter; 2010. p.83-7. 
Friedman M, Ibrahim H, Joseph NJ. Staging of Obstructive Sleep Apnea/ Hypopnea Syndrome: A Guide to Appropriate Treatment. Laryngoscope. 2004;114:454-9.

Guimarães KC, Drager LF, Genta PR, Marcondes BF, Lorenzi-Filho G. Effects of Oropharyngeal Exercises on Patients with Moderate Obstructive Sleep Apnea Syndrome. Am J Respir Crit Care Med. 2009; 179: 962-6.

Iber C, Ancoli-Israel S, Chesson Jr A, Quan S. The AASM Manual for the Scoring of Sleep and Associated Events: Rules, Terminology and Technical Specifications. Westchester, IL: American Academy of Sleep Medicine, 2007.

Iseri M, Balcioglu O. Radiofrequency versus injection snoreplasty in simple snoring. Otolaryngol Head Neck Surg. 2005;133: 224-8.

Johns MW. A new method for measuring daytime sleepiness: the Epworth Sleepiness Scale. Sleep. 1991;14: 540-5.

Jones TM, Walker P, Ho MS, Earis JE, Swift AC, Charters, P. Acoustic parameters of snoring sound to assess the effectiveness of sleep nasendoscopy in predicting surgical outcome. Otolaryngol Head Neck Surg. 2006;135(2):269-75. 
Levinson SR. Injection Snoreplasty. Otolaryngol Head Neck Surg 2001; 125(5): 579-80.

Lopes RP, Gomes LG, Ramos D, Jamur MC, Oliveira JAA, Fomin DS. Injeção de substancia esclerosante na base da língua: modelo experimental para tratamento da SAOS. Rev Bras Otorrinolaringol. 2002;68(6):834-7.

Lorenzetti FTM, Formigoni GGS, Cahali MB. Uma nova proposta de nomenclatura: "Injeção Roncoplástica”. Rev Bras Otorrinolaringol. 2008;74 (3):327.

Lugaresi E, Cirignotta F, Piana G. Some epidemiological data on snoring and cardiocirculatory disturbances. Sleep. 1980; 3: 221-4.

Powell NB, Riley RW, Troell RJ, Li K, Blumen MB, Guilleminault C. Radiofrequency Volumetric Tissue Reduction of the Palate in Subjects With Sleep-Disordered Breathing. Chest. 1998;113:1163-74.

Poyrazoglu E, Dogru S, Saat B, Gungor A, Cekin E, Cincik H. Histologic effects of injection snoreplasty and radiofrequency in the rat soft palate. Otolaryngol Head Neck Surg. 2006;135(4):561-4. 
Robertson S, Murray M, Young D, Pilley R, Dempster J. A randomized crossover trial of conservative snoring treatments: Mandibular repositioning splint and nasal CPAP. Otolaryngol Head Neck Surg. 2008;138(3):283-8.

Savage CR, Steward DL. Snoring: a critical analysis of current treatment modalities. Does anything really work? Curr Opin Otolaryngol Head Neck Surg. 2007;15:177-9.

Strauss JF. A new approach to the treatment of snoring. Arch Otolaryngol. $1943 ; 38: 225-9$.

Stuck BA, Kopke J, Hormann K, Verse T, Eckert A, Bran G, Duber C, Maurer JT. Volumetric tissue reduction in radiofrequency surgery of the tongue base. Otolaryngol Head Neck Surg. 2005;132(1):132-5.

Stuck BA, Maurer JT. Airway evaluation in obstructive sleep apnea. In: Friedman M, editor. Sleep Apnea and Snoring. Surgical and Non-Surgical Therapy. $1^{\text {a }}$ ed. Chicago: Saunders Elsevier; 2009. p.11-21.

Tufik S, Santos-Silva R, Taddei JÁ, Bittencourt LR. Obstructive sleep apnea syndrome in the Sao Paulo Epidemiologic Sleep Study. Sleep Med. 2010; 11(5): 441-6. 
Young T, Palta M, Dempsey J, Skatrud J, Weber S, Badr S. The occurrence of sleep-disordered breathing among middle aged adults. $N$ Engl $J$ Med. 1993;328:1230-5.

Zonato Al. Avaliação otorrinolaringológica dos pacientes com SAOS. In: Pinto JA, editor. Ronco e Apneia do Sono. $2^{\mathrm{a}}$ ed. Rio de Janeiro: Revinter; 2010. p.75-81. 
APÊNDICES 


\section{APÊNDICE 1}

\section{Carta da Comissão de Ética}

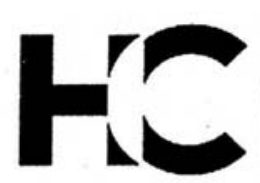

\section{HAS RLIMBRS}

\section{APROVAÇÃO}

A Comissão de Ética para Análise de Projetos de Pesquisa - CAPPesq da Diretoria Clínica do Hospital das Clínicas e da Faculdade de Medicina da Universidade de São Paulo, em sessão de 10.08.05, APROVOU o Protocolo de Pesquisa $n^{\circ}$ 508/05, intitulado: "Injeção de substâncias esclerosantes em palato mole: uma nova terapia para roncopatias" apresentado pelo Departamento de OFTALMOLOGIA E OTORRINOLARINGOLOGIA, inclusive o Termo de Consentimento Livre e Esclarecido.

Cabe ao pesquisador elaborar e apresentar à CAPPesq, os relatórios parciais e final sobre a pesquisa (Resolução do Conselho Nacional de Saúde $n^{\circ} 196$, de 10.10.1996, inciso IX. 2, letra "c")

Pesquisador(a) Responsável: Dr Michel Burihan Cahali Pesquisador (a) Executante: Dr Fábio Tadeu Moura Lorenzeti

CAPPesq, 10 de Agosto de 2005.

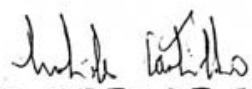

PROF. DR. EUCLIDES AYRES DE CASTILHO Presidente da Comissão de Ética para Análise de Projetos de Pesquisa 


\title{
APÊNDICE 2
}

\section{Termo de Consentimento Livre e Esclarecido}

\author{
Anexo \\ HOSPITAL DAS CLÍNICAS \\ DA \\ FACULDADE DE MEDICINA DA UNIVERSIDADE DE SÃO PAULO
}

TERMO DE CONSENTIMENTO PÓS -INFORMAÇÃO

I - DADOS DE IDENTIFICAÇÃO DO SUJEITO DA PESQUISA OU RESPONSÁVEL LEGAL

1. NOME DO PACIENTE

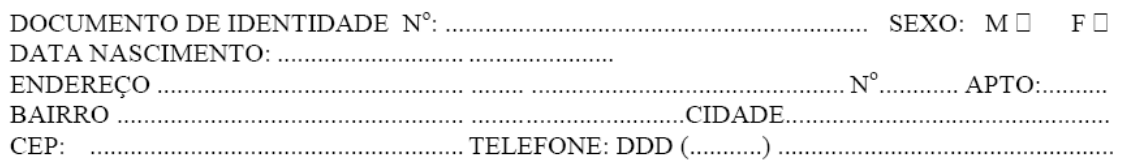

2. RESPONSÁVEL LEGAL

NATUREZA (grau de parentesco, tutor, curador etc.)

DOCUMENTO DE IDENTIDADE: ............................................................. SEXO: M $\square \quad$ F

DATA NASCIMENTO: ...................................................

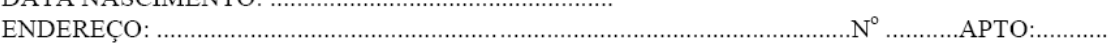

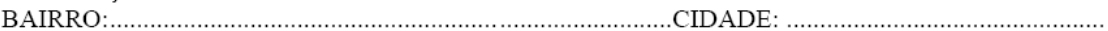

CEP:

\section{II - DADOS SOBRE A PESQUISA CIENTÍFICA}

1. TÍTULO DO PROTOCOLO DE PESQUISA:Injeção de substâncias esclerosantes em palato mole: uma nova terapia para roncopatias

2. PESQUISADOR: Dr. Fábio Tadeu Moura Lorenzetti

CARGO/FUNÇÃO: Pós graduando e ex-residente de otorrinolaringologia do HCFMUSP.

INSCRIÇAO CONSELHO REGIONAL N ${ }^{\circ} 95864$

UNIDADE DO HCFMUSP: DIVISÃO DE CLÍNICA OTORRINOLARINGOLÓGICA

3. AVALIAÇÃO DO RISCO DA PESQUISA:

$\begin{array}{lll}\text { SEM RISCO } \square & \text { RISCO MÍNIMO } \square & \text { RISCO MÉDIO } \square \\ \text { RISCO BAIXO X } & \text { RISCO MAIOR } \square\end{array}$

(probabilidade de que o indivíduo sofra algum dano como consequência imediata ou tardia do estudo) 4. DURAÇÃO DA PESQUISA: Dois anos e meio

III - REGISTRO DAS EXPLICAÇÕES DO PESQUISADOR AO PACIENTE OU SEU REPRESENTANTE LEGAL SOBRE A PESQUISA, CONSIGNANDO:

1. justificativa e os objetivos da pesquisa; 2 . procedimentos que serão utilizados e propósitos, incluindo a identificação dos procedimentos que são experimentais; 3 . desconfortos e riscos esperados; 4. benefícios que poderão ser obtidos; $\mathbf{5}$. procedimentos alternativos que possam ser vantajosos para o indivíduo.

A uvulopalatofaringoplastia é uma cirurgia realizada desde 1979 para o tratamento da apnéia obstrutiva do sono (parar de respirar quando está dormindo) e desde 1964 para o tratamento dos roncos. Os resultados são variáveis e a cirurgia tem mais sucesso no tratamento dos roncos do que da apnéia do sono. 
Uma nova alternativa de tratamento tem sido realizada nos Estados Unidos há mais de 4 anos: a injeção de substância esclerosante no palato (garganta), com resultados animadores. Desta forma estamos avaliando esta nova terapia aqui no Brasil. Para isto, sob anestesia com spray de Lidocaína, será injetada uma substância esclerosante (Ethamolin ou Etanol 50\%) no palato de alguns pacientes, através de uma seringa com agulha fina. O procedimento produz dor leve no local, porém a intenção é de promover endurecimento e retração do tecido, com melhora do ronco. Estas substâncias já são utilizadas rotineiramente em medicina, sobretudo para esclerose de varizes. No entanto, pacientes com história de alergia à alguma destas drogas não devem participar deste estudo.

Antes e depois do tratamento, serão realizados questionários e exames: nasofibrolaringoscopia (passagem de um pequeno aparelho para visualizar o interior do nariz e da garganta), polissonografia (dormir no laboratório para registro o sono) e ressonância nuclear magnética (permanecer dentro de um aparelho por alguns minutos).

Como alternativa de tratamento, todos os pacientes podem usar um aparelho chamado de CPAP, que poderá ser utilizado também se o procedimento não funcionar. Este aparelho empurra o ar para dentro do nariz sendo bastante efetivo no tratamento, porém, é muito incômodo para algumas pessoas e deve ser usado todas as noites para o resto da vida. Este tratamento com CPAP não é fornecido pelo hospital e nem pelo Sistema Único de Saúde até o momento.

\section{IV - ESCLARECIMENTOS DADOS PELO PESQUISADOR SOBRE GARANTIAS DO SUJEITO DA PESQUISA:}

1. acesso, a qualquer tempo, às informações sobre procedimentos, riscos e benefícios relacionados à pesquisa, inclusive para dirimir eventuais dúvidas.

2. liberdade de retirar seu consentimento a qualquer momento e de deixar de participar do estudo, sem que isto traga prejuízo à continuidade da assistência.

3. salvaguarda da confidencialidade, sigilo e privacidade.

4. disponibilidade de assistência no HCFMUSP, por eventuais danos à saúde, decorrentes da pesquisa.

5. viabilidade de indenização por eventuais danos à saúde decorrentes da pesquisa.

\section{INFORMAÇÕES DE NOMES, ENDEREÇOS E TELEFONES DOS RESPONSÁVEIS PELO ACOMPANHAMENTO DA PESQUISA, PARA CONTATO EM CASO DE INTERCORRÊNCIAS CLINICAS E REAÇÕES ADVERSAS.}

Dr.FÁBIO TADEU MOURA LORENZETTI

Tel: 3069-6288 (secretaria ORL), 3069-6000 (ramal 6581) (pronto-socorro) e 3069-6385 (ambulatório)

\section{VI - OBSERVACÕES COMPLEMENTARES}

O paciente autoriza o pesquisador a divulgar os dados do estudo, incluindo os exames radiológicos e fotos/vídeos de exames pré e pós-operatórios e da cirurgia, preservando a identidade do paciente.

\section{VII - CONSENTIMENTO PÓS-ESCLARECIDO}

Declaro que, após convenientemente esclarecido pelo pesquisador e ter entendido o que me foi explicado, consinto em participar do presente Protocolo de Pesquisa.

São Paulo ..de 